\title{
The Impact of the COVID-19 Pandemic on Dementia Risk: Potential Pathways to Cognitive Decline
}

\author{
Jeffrey D. Pyne Adam M. Brickman \\ Department of Neurology, Taub Institute for Research on Alzheimer's Disease and the Aging Brain, College of \\ Physicians and Surgeons, Columbia University, New York, NY, USA
}

\section{Keywords}

Coronavirus disease 2019 . Severe acute respiratory syndrome coronavirus 2 . Dementia risk - Cognitive decline . Neurological symptoms

\begin{abstract}
Background: Coronavirus disease 2019 (COVID-19), the farreaching pandemic, has infected approximately 185 million of the world's population to date. After infection, certain groups, including older adults, men, and people of color, are more likely to have adverse medical outcomes. COVID-19 can affect multiple organ systems, even among asymptomatic/mild severity individuals, with progressively worse damage for those with higher severity infections. Summary: The COVID-19 virus, severe acute respiratory syndrome coronavirus 2 (SARS-CoV-2), primarily attaches to cells through the angiotensin-converting enzyme 2 (ACE2) receptor, a universal receptor present in most major organ systems. As SARSCoV-2 binds to the ACE2 receptor, its bioavailability becomes limited, thus disrupting homeostatic organ function and inducing an injury cascade. Organ damage can then arise from multiple sources including direct cellular infection, overactive detrimental systemic immune response, and ischemia/
\end{abstract}

hypoxia through thromboembolisms or disruption of perfusion. In the brain, SARS-CoV-2 has neuroinvasive and neurotropic characteristics with acute and chronic neurovirulent potential. In the cardiovascular system, COVID-19 can induce myocardial and systemic vascular damage along with thrombosis. Other organ systems such as the lungs, kidney, and liver are all at risk for infection damage. Key Messages: Our hypothesis is that each injury consequence has the independent potential to contribute to long-term cognitive deficits with the possibility of progressing to or worsening pre-existing dementia. Already, reports from recovered COVID-19 patients indicate that cognitive alterations and long-term symptoms are prevalent. This critical review highlights the injury pathways possible through SARS-CoV-2 infection that have the potential to increase and contribute to cognitive impairment and dementia.

(c) 2021 S. Karger AG, Base

\section{Introduction}

The coronavirus disease 2019 (COVID-19) pandemic, caused by the severe acute respiratory syndrome coronavirus 2 (SARS-CoV-2), has affected every aspect of global \\ Karger"}


society, including alarming alterations to public health, medical care access, and the global economy. To date, approximately 185 million of the global population has been infected with significant risk for more infections in the future [1]. Mutations to the SARS-CoV-2 virus have the potential to amplify the number of future COVID-19 cases through higher infectivity rates and vaccine-resistant strains [2]. While recent vaccination efforts are effective and have the potential to curtail the widespread SARSCoV-2 infections as well as to decrease infection severity, those already affected and those with infections to come will experience the brunt of the long-term health consequences. Our proposition is that the long-term health consequences of COVID-19 could manifest as cognitive decline in some people.

Below, we first outline the mechanism by which SARSCoV-2 infects cells, how infection utilization can compound organ damage, and provide possible routes for the virus to infect the brain directly. Then, we review neurological symptoms and neuroimaging findings in COVID-19 patients, neuropathology seen from autopsy studies, and subsequent cognitive alterations and longterm symptoms exhibited in recovered COVID-19 patients. The processes by which COVID-19 affects the brain are interdependent and happen through multiple independent pathways. A critical subset of pathways to brain injury, covered next, include cardiovascular interactions and organ damage to the lungs, kidney, and liver. Understanding the mechanism by which COVID-19 affects the body then allows us to speculate why some groups of people, including those with cardiovascular risk factors, those of older age, people of color in the USA, and men, experience a disproportionate impact from SARS$\mathrm{CoV}-2$ infection with poorer medical outcomes relative to other groups [3]. Notably, most of these groups are at particularly elevated risk for dementia [4], with COVID-19 potentially acting additively or synergistically with pre-existing comorbidities to contribute to the onset or progression of cognitive impairment and dementia.

Overall, this critical review synthesis examines possible viral infection pathways to the brain, interactions between the SARS-CoV-2 virus infection and multiple critical organ systems, and the implications of COVID-19 for short-term neurological consequences and long-term dementia risk. Our hypothesis is that SARS-CoV-2 infection, due to plausible COVID-19 cognitive decline pathways, evidence of prevalent neurological symptoms in patients, and relevant long-term symptoms in recovered individuals, promotes risk for cognitive decline and has the potential to exacerbate pre-existing dementia.

\section{SARS-CoV-2 General Infection Characteristics}

To understand why COVID-19 can increase dementia risk, we must start with how SARS-CoV-2 is exposed to, enters, and damages the body. The primary mode of SARS-CoV-2 infection is through respiratory droplets that spread from an infected person. Infection occurs when these droplets are introduced directly to the lungs/mouth/nose of a noninfected individual through breathing inhalation and/or surface transfer (fomite transmission) [5]. After this introduction, the virus travels to organs throughout the body, where it directly or indirectly influences each organ's respective functions. According to biopsy and autopsy findings from SARS-CoV-2-positive individuals, direct SARS-CoV-2 infections can be found in the lungs $[6,7]$, brain [8], heart [9], kidney [10], liver [11], cerebral spinal fluid (CSF) $[12,13]$, lymph nodes $[7,14]$, spleen $[7,14]$, intestines [7], and testes [7]. Additionally, widespread viral organ damage has been observed in the lungs, brain, heart, kidney, liver, and gut, highlighting the potential systemic influence of the virus throughout the body [15]. While more extensive autopsy findings are still needed to understand the full extent of the direct SARSCoV-2 infection, it is clear that organ damage also occurs from indirect immune responses. This widespread propensity of SARS-CoV-2 is due to the mechanism of the viral pathway, specifically the cellular attachment points that are found in most organ systems and their relationship with cardiovascular and immune systems. This mechanism underlies the injury cascade from $\mathrm{CO}$ VID-19 and provides an important context for our conclusions regarding how COVID-19 can affect longterm cognitive function.

\section{SARS-CoV-2 Viral Entry (Angiotensin-Converting}

Enzyme 2, Host Proteases, and NRP1)

To initiate viral replication, SARS-CoV-2 attaches to healthy cell membranes primarily through the angiotensin-converting enzyme 2 (ACE2) receptor present within many organs systems [16]. ACE2 receptors are found in the lungs $[17,18]$, brain $[18,19]$, kidneys $[17,18]$, intestines $[17,18]$, female organs [20], male organs $[17,18]$, heart [17-19], colon [17], liver [17, 19], adipose tissue [16, 19], vasculature [18, 19], stomach [19], central nervous system [16], thyroid [20], adrenal gland [20], muscle [20], bone marrow [20], blood [20], and nasal and oral mucosa [19]. The highest ACE2 expression is in the gastrointestinal tract, male reproductive system, kidney, gallbladder, heart, and thyroid $[20,21]$. 
Notably, the presence of ACE2 alone is not sufficient for SARS-CoV-2 cellular infection. A host cell protease, such as transmembrane protease serine 2 (TMPRSS2), cathepsin L, or furin, is also required for SARS-CoV-2 Spike (S) protein priming [22-24]. Other important host cell entry factors, such as the protein Neuropilin-1 (NRP1), can enhance the infectivity of SARS-CoV-2 after furin cleaves the viral S protein into the subsequent S1 and S2 proteins $[25,26]$. All of these proteases can be found throughout the body with TMPRSS2, for example, being found in the cardiovascular system, heart, kidney, and lungs with medium confidence, and found in the brain and central nervous system with low confidence [27]. For neurological considerations, both ACE2 and TMPRSS2 receptors have been discovered in the head and neck regions, specifically within sustentatorial, stem neuronal, epithelial, goblet, and oligodendrocytes cell types [28,29]. Additionally, furin may play an important role in the central nervous system due to its high protein prevalence in the cerebral cortex, hippocampus, and cerebellum [22]. NRP1 is expressed in endothelial cells, olfactory epithelium, vascular smooth muscle cells, vascular macrophages, and neurons with evidence NRP1 could be implicated in the neurological disruption of COVID-19 [30]. While the absolute amount of ACE2 receptors and various proteases are related to a tissue's direct infection risk [29] (dependent on the SARS-CoV-2 virus reaching that tissue), these factors do not fully represent the degree of subsequent injury risk.

\section{Organ Injury through SARS-CoV-2-Induced ACE2}

Deficiencies

The importance and function of ACE2 should be highlighted to understand how organ injury is initiated after SARS-CoV-2 infection. ACE2 is a component of the renin-angiotensin-aldosterone system, which partially regulates cardiovascular function such as arterial blood pressure, total blood volume, and vascular remodeling [31, 32]. In particular, ACE 2 acts as a negative regulation component by promoting vasodilation and hypotension [33]. Thus, ACE2 is typically considered to be cardioprotective, renoprotective, hepatoprotective, and protective against fibrosis [17, 34].

As SARS-CoV-2 infects healthy cells, it decreases the bioavailability of ACE2 receptors within the renin-angiotensin-aldosterone system. ACE2 deficiency can result in organ injury through uncontrolled nonspecific inflammation (cytokine storm [35]) as well as increased coagulation, increased fibrinolysis, myocardial injury [36], increased vascular permeability [27], and acute lung injury

COVID-19 Dementia Risk
[37]. For those with pre-existing ACE2 deficiencies before SARS-CoV-2 infection, such as individuals with hypertension, diabetes mellitus, and those of older age, the risk of more severe symptoms is increased due to the lack of ACE2 bioavailability as the infection spreads $[18,38]$. Additionally, the degree of induced inflammation and risk of detrimental cytokine storm, through ACE2 deficiency due to SARS-CoV-2 infection, is dependent on sex and age $[20,39,40]$.

In the brain, the loss of ACE2 bioavailability impairs blood pressure control and autoregulation ability in the form of altered baroreflex sensitivity and endothelial cell function [19, 41, 42]. Mechanistically, endothelial cells, smooth muscle cells, glial cells, and neurons all utilize ACE2 for proper function [41] in many brain regions [43]. Consequently, brain levels of ACE2 are relevant for the degree of ischemic injury and its subsequent potential impact on neurodegeneration, Alzheimer's disease (AD), and dementia risk [43-45]. ACE2 levels are accordingly inversely correlated with parenchymal amyloid beta and tau in $\mathrm{AD}$ [46]. For cases of COVID-19, where cardiovascular and cerebral ACE2 receptors are taken up by the SARS-CoV-2 virus, acute exasperation of these ACE2 limited effects could contribute to neurological symptoms. Another potential contributor to neurological symptoms, and a pathway to cognitive decline, is the direct cerebral infection risk posed by SARS-CoV-2. Below, we will discuss these direct pathways to the brain, the neurological symptoms present in COVID-19 patients, the implications of direct brain infection, types of neuropathology observed, and cognitive alterations and longterm symptoms reported from recovered COVID-19 patients.

\section{SARS-CoV-2 Neurological Infection Characteristics}

\section{Cerebral Viral Pathway - Neuroinvasive and Neurotropic}

From a neurological perspective, it is important to understand how SARS-CoV-2 potentially infects the cerebrum and the consequential clinical implications. The SARS-CoV-2 virus is classified as a human betacoronavirus, joining the ranks of other epidemic-causing viruses such as SARS-CoV-1 and Middle East respiratory syndrome-related coronavirus (MERS-CoV) [47]. Human coronaviruses, including at least human coronavirus 229E (HCoV-229E, common cold), human coronavirus OC43 (HCoV-OC43, common cold), and SARS-CoV-1 (SARS), have both neuroinvasive and neurotropic prop- 
erties [47-49], which refer, respectively, to the ability to invade the central nervous system from the periphery and the ability to directly infect neurons and glial cells [48]. Potentially due to being structurally/genetically similar to SARS-CoV-1 [50], SARS-CoV-2 also appears to exhibit neuroinvasive [12] and neurotropic [8] properties.

There are multiple possibilities for SARS-CoV-2 neuroinvasive pathways, including neural and hematogenous routes $[49,51,52]$. One possibility for the neural route is through the olfactory nerves, where SARS-CoV-2 potentially utilizes axonal and transneuronal transport to enter the central nervous system [51]. This pathway is directly supported by findings of SARS-CoV-2 infection of neurons in the olfactory mucosa [53] and low levels of SARS-CoV-2 ribonucleic acid in the olfactory bulb [54]. This possibility was also demonstrated with the SARS$\mathrm{CoV}-1$ virus in intranasally inoculated mice $[51,52]$. Of note, NRP1 could play a role in the neural pathway by enhancing the infectivity of SARS-CoV-2 into olfactory neurons [30]. While the neural route is a slow transport mechanism, considering the proximity of the olfactory nerve to the brain, it could be a cause of early cerebral infection as well as induce olfactory symptoms [52]. In 1 patient with SARS-CoV-2 infection and anosmia, magnetic resonance imaging (MRI) revealed abnormalities within the right gyrus rectus and olfactory bulbs early in the infection timeline [55]. Overall, up to $64 \%$ of clinical COVID-19 patients have olfactory dysfunction, which could be partially caused by this infection route, though changes significant enough to be visualized in MRI may only occur in the earliest phase of the infection or in subsets of the population $[55,56]$. The axonal transport through the olfactory bulb could have specific consequences for the hippocampus and entorhinal cortex. These brain regions are positioned in close proximity to the olfactory bulb and contain direct neuron projections connecting these territories [57]. Both the hippocampus and the entorhinal cortex are regions involved in early $\mathrm{AD}$ progression [58] and injury by SARS-CoV-2 could have implications for cognitive decline.

The hematogenous route, shown to be possible in SARS-CoV-1-infected mice, would take the form of SARS-CoV-2 passing through the blood-brain barrier $(\mathrm{BBB})$ and appears possible in humans $[8,52]$. This hematogenous pathway, while not mutually exclusive from the neural pathway, could exploit increased BBB permeability from systemic inflammation (from cytokine and/ or bradykinin storms) or could exploit direct endothelial cell infection to enter the brain $[52,59,60]$. If infectious SARS-CoV-2 virions were to pass through a leaky BBB, they would travel in blood unaided or could exploit transport through an infected cell. While infectious SARSCoV-2 virions have not been confirmed in blood, noninfectious SARS-CoV-2 ribonucleic acid has been confirmed, highlighting the potential for this pathway [61]. The exact mechanism for SARS-CoV-2 to infect blood is currently unknown, but one possibility is for SARSCoV-2 to infect lymphoid tissue directly, shown possible in humans $[7,14]$, and then transfer to blood via lymph fluid [52]. The direct infection through CSF appears to be rare with only $6 \%$ of patients with central nervous symptoms testing positive for SARS-CoV-2 in the CSF, suggesting that indirect inflammatory damage may play a larger role in COVID-19 [62]. Alternatively, infected leukocytes could act as a carrier of viral particles to aid viral entry across the BBB [59]. As this hematogenous pathway may be dependent on BBB permeability (driven from neuroinflammation or cerebral hypoxia [63]), it is possibly a later stage neuroinfection route. Individuals with pre-existing BBB dysfunction, such as those with hypertension, diabetes, older age, cerebrovascular disease [64], and neurodegenerative disease (AD, Parkinson's disease, and multiple sclerosis [65]), could be particularly vulnerable. It is worth noting that these same groups with preexisting BBB dysfunction, those with cardiovascular risk factors, those of older age [3], and those with neurodegenerative diseases $[66,67]$ are all at elevated risk for a more severe COVID-19 course, including death. While there may be multiple explanations for poorer outcomes among older adults and those with cardiovascular risk factors, detailed below, poorer outcomes among those with neurodegenerative diseases could be explained by ACE2 disruption, BBB dysfunction, or higher rates of NRP1 expression [68]. Additionally, elevated COVID-19 severity and death risk are correlated with the presence of neurological symptoms [69], indicating a connection between neurological involvement and COVID-19 disease course.

\section{SARS-CoV-2 Neurological Symptoms/Manifestations}

Regardless of viral pathway, reports of COVID-19 commonly show a diverse set of neurological symptoms that can be classified as central nervous system, peripheral nervous system, and skeletal muscular injury involvement [70]. Neurological clinical symptoms, split into severe and non-severe COVID-19 cases along with unspecified or case studies, are represented in Table 1. Overall, at least 1 neurological symptom is present within $46-93 \%$ of severe and 30-79\% of non-severe COVID-19 clinical patients [71-73]. Typically, patients will experi- 
Table 1. Rate estimations of neurological symptoms, loosely organized by frequency, are broken down into central nervous system, peripheral nervous system, and skeletal muscular injury categories, among clinical COVID-19 patients

\begin{tabular}{|c|c|c|c|c|}
\hline & Neurological manifestation & Severe case & Non-severe case & $\begin{array}{l}\text { Unspecified severity } \\
\text { or case studies }\end{array}$ \\
\hline \multirow[t]{10}{*}{ Central nervous system } & Encephalopathy & $65-84 \%[71,75]$ & $13 \%[71]$ & $42 \%[76]$ \\
\hline & Dizziness & $5-30 \%[71-73,77]$ & $7-30 \%[71-73,77]$ & - \\
\hline & Headache & $8-32 \%[71-73,77]$ & $6-40 \%[71,73,77,78]$ & - \\
\hline & Altered state of consciousness & $5-39 \%[71-73]$ & $2-7 \%[71-73]$ & $33 \%[76]$ \\
\hline & Nausea/vomiting & $8-11 \%[77]$ & $2-10 \%[77,78]$ & - \\
\hline & Ischemic stroke & $1.2-5.7 \%[71-73,82]$ & $0.5-1.4 \%[71-73,82]$ & $1.6-5.4 \%[76,83]$ \\
\hline & Acute hemorrhage & $0.7-0.9 \%[71,73]$ & $0 \%[71,73]$ & $4.5 \%[76]$ \\
\hline & Acute encephalitis & $0 \%[71,73]$ & $0.2-0.3 \%[71,73]$ & $-[12]$ \\
\hline & Meningitis/myelitis & $0 \%[71]$ & $0 \%[71]$ & $-[12,84]$ \\
\hline & Ataxia & $1.1 \%[72]$ & $0 \%[72]$ & - \\
\hline \multirow{3}{*}{$\begin{array}{l}\text { Peripheral nervous } \\
\text { system }\end{array}$} & Vision impairment & $2.3 \%[72]$ & $0.8 \%[72]$ & - \\
\hline & Polyneuropathy & $0-1.5 \%[71,73]$ & $0-0.2 \%[71,73]$ & - \\
\hline & Guillain-Barré syndrome + variants & $0 \%[71]$ & $0 \%[71]$ & $0.004-0.005 \%$ [86-89] \\
\hline \multirow[t]{2}{*}{ Skeletal muscular injury } & Myalgias & $42-65 \%[71,73]$ & $10-53 \%[71,73,90]$ & - \\
\hline & Rhabdomyolysis & $2.2-13 \%[71,73]$ & $0.3-0.4 \%[71,73]$ & - \\
\hline Overall & & $46-93 \%$ [71-73] & 30-79\% [71-73] & - \\
\hline
\end{tabular}

COVID-19, coronavirus disease 2019. Severe versus non-severe COVID-19 cases were distinguished based on respiratory/pneumonia metrics with severe cases passing the criterion for mechanical ventilation [71, 76].

ence between 1 and 3 neurological symptoms throughout the course of COVID-19 [71]. Of note, the major differences between severe and non-severe cases can include encephalopathy, altered state of consciousness, cerebral ischemic stroke, rhabdomyolysis, taste, and smell impairment $[71,73]$. The more rare symptoms include cerebral hemorrhage, encephalitis, meningitis/myelitis, ataxia, seizures, polyneuropathy, and Guillain-Barré syndrome [74]. Typically, more severe COVID-19 cases are associated with increased likelihood of neurological symptoms $[51,72]$, which have the potential to occur anytime over the duration of the infection [71]. While disentanglement of infection root causes of neurological symptoms is difficult, in any case there are potential long-term consequences for the individual [70].

\section{SARS-CoV-2 Neurovirulent Potential}

With the establishment of neuroinvasive and neurotropic characteristics for SARS-CoV-2 as well as clinical neurological symptoms, it remains to be seen if the virus has neurovirulence or will induce neurological diseases in humans. These possible neurological diseases range from acute forms such as encephalitis, to postinfectious encephalomyelitis, to the induction of neurodegeneration $[48,91]$. Viral acute encephalitis, direct neuroinflammation of gray matter, is typically characterized by neuronal death (either directly from viral replication or immune response), perivascular inflammation, and tissue necrosis [92]. Postinfectious encephalomyelitis is more typically associated with white matter damage through demyelination and perivascular inflammation and occurs days to weeks after the infection seemingly is cleared $[91,92]$. The initiation of viral acute encephalitis has been documented in humans across multiple viruses including herpes simplex virus (HSV), rabies virus, Japanese B encephalitis, measles, mumps, and rubella $[48,91]$. For cases of chronic viral-induced neurodegeneration, viruses such as herpes simplex virus type 1 (HSV-1) and human herpes virus 6 (HHV-6) have been hypothesized to promote or exacerbate $\mathrm{AD}$, while human immunodeficiency virus (HIV) 
has been causally linked to neurodegeneration [48]. Congruent with the neurological impact of HSV-1, HHV-6, and HIV, a proposed underlying theory for neurovirulence states that neuroinflammation consequences from any viruses, bacteria, and/or fungal infection source could contribute to AD pathogenesis [93]. For neurotropic and neuroinvasive human coronaviruses, the connection with chronic neurovirulent properties is not yet established. That said, in animal models, several respiratory coronaviruses have neurovirulent properties including the mouse hepatitis virus, porcine hemagglutinating encephalomyelitis virus, and feline coronavirus [48]. Therefore, it is important to investigate the neurovirulence potential of SARS-CoV-2 in both acute and chronic possibilities.

The most extreme forms of SARS-CoV-2 acute neurovirulence would include meningitis or encephalitis. While there have been reported cases of meningitis/encephalitis in human patients with SARS-CoV-2 [12, 13, 94], the total extent and chronic hazard are less clear. To explore the source of this encephalitis/neuroinflammation, neurovirulent viruses can directly produce proinflammatory signaling in the brain [95]. The primary cells responsible for immune system signaling in the brain, astrocytes and microglia, produce higher signaling levels specifically with neurotropic viral infection [95]. Patients with moderate and severe COVID-19 have evidence of astrocytic activation and injury [96], suggesting neurotropic properties of SARS-CoV-2 that possibly induces this proinflammatory signaling. Additionally, there are increased concentrations of plasma neurofilament light protein in severe COVID-19 patients, suggesting neuronal injury as the disease progresses [96]. In murine models, SARS-CoV-2 infection causes direct astrocytes, microglia, and neuronal infection [97]. These observations have implications for neurotropic viruses, as the activation of neuroinflammation presents a potential pathway to acute neurovirulence and/or chronic neurodegeneration $[98,99]$. While these human and animal findings provide evidence that part of the neuroinflammation could be directly occurring from SARS-CoV-2 neurotropism, systemic inflammation may also influence the immune signaling of astrocytes and $\mathrm{mi}-$ croglia. In particular, mere exposure to proinflammatory cytokines, expressed from the periphery, could increase the permeability of the BBB (increasing likelihood of direct viral infection) as well as influence astrocytes in such a way to induce neurodegeneration and further neuroinflammation [100]. Therefore, the generation, quantity, and type of periphery proinflammatory cytokines play an important role in neurodegeneration [98]. Regardless of whether SARS-CoV-2 directly uses astrocytes as viral hosts or influences them from indirect periphery signals, there are multiple pathways to acute neurovirulence that need to be further researched to understand exactly how the brain is affected [100].

Establishing the chronic neurovirulence potential of SARS-CoV-2 is difficult early in the timeline of the COVID-19 pandemic, especially among individuals with mild COVID-19 symptoms, but certain essential traits such as persistence of virus within the central nervous system can establish the risk potential for chronic pathogenesis. Similar to how HSV-1 can persist in human brains throughout a lifetime [101], some human coronaviruses could have this capability. For example, $\mathrm{HCoV}$ 229E and HCoV-OC43 have the ability to infect neural cells persistently (for at least 130 days) as well as to produce infectious virions throughout the infection duration $[102,103]$. These particular human coronaviruses are not known to express any chronic neurovirulent properties, but other neurovirulent viruses such as HSV-1, HHV-6, and HIV can act as a template for determining the warning signs of potential long-term SARS-CoV-2 risk [48]. Additionally, chronic neuroinflammation is present across many neurodegenerative diseases and plays a role in the disease progression for Parkinson's disease and AD as well as psychiatric diseases such as schizophrenia, bipolar disorders, and substance abuse [104, 105]. Chronic neuroinflammation has the potential to initiate or worsen pre-existing neurodegeneration; understanding the role of SARS-CoV-2 infection on chronic neuroinflammation will be critical for long-term treatment $[104,106]$. Especially important for younger individuals and those with mild/asymptomatic cases of COVID-19 will be determining if chronic neuroinflammation is present and if so, the extent [105]. While neurovirulent characteristics can be difficult to substantiate, neuropathology and neuroimaging can provide insight into potential risk.

\section{Neuropathology and Neuroimaging}

Damage to the central nervous system from viral infection can occur through three separate pathways. The first pathway is direct damage to cells through viral replication, termed virus-induced neuropathology [48]. The second pathway is indirect cell damage originating from an overactive immune response, designated virus-induced neuroimmunopathology [48]. The third pathway is through systemic/cerebrovascular disorder that includes cellular hypoxia (driven by hypoperfusion, arterial thromboembolism, and/or acute respiratory distress), sepsis, hyperpyrexia, and hypercoagulability [107]. To- 
gether, these pathways comprise the neuropathological possibilities of COVID-19 and can exist independently of each other. Seemingly consistent with the neurovirulence hypothesis of SARS-CoV-2, autopsy and MRI studies confirm aspects of expected acute damage. Since categorizing the root causes of downstream cerebral damage is not always possible without more in-depth analysis, along with the challenge of untangling pathology from pre-existing comorbidities, all the following MRI and neuropathology findings will not be binned into pathways except for some specific cases. Observed neuropathology includes focal hemorrhagic white matter lesions [107, 108], discrete foci of acute axonal injury (with myelin loss) [108], florid leukocytoclastic reaction within infarcts, lymphohistiocytic inflammation [109], and neuronal cell loss [110]. Overall, neuropathology of these types is more consistent with immune-mediated damage or hypoxia than direct virus-induced neuropathology [54, 108], especially since SARS-CoV-2 virus is not always found in the injured brain [111] or is found at very low levels [54]. For example, demyelination is consistent with immunemediated damage such as in cases of Guillain-Barré syndrome or acute disseminated encephalomyelitis [107], though demyelination may not be a common feature of COVID-19 [54]. The leukocytoclastic and lymphohistiocytic reactions are interesting because they could hint at neuroimmunopathological roots or may be a typical reaction to reperfusion injury within infarct regions [109]. Other neuropathology, potentially indicative of systemic/ cerebrovascular disorder, has cerebral manifestations of neocortical infarcts $[54,108]$, scattered shrunken/necrotic neurons [54, 108, 110], microhemorrhage [107], and acute hypoxic ischemic damage $[54,112]$. The degree of stroke, clot, and hypoxic/ischemic damage seen across clinical COVID-19 cases means that a portion of this damage can be attributed to thrombotic origins. While this establishes the neuropathological possibilities within patients who have died from fatal COVID-19 complications, the neurological implications for moderate, mild, and asymptomatic COVID-19 patients are less clear.

To explore the domain of COVID-19 patients who survive the initial infection, clinical brain imaging can offer insights into potential damage. In general, clinical imaging supports neuropathological findings with acute/ chronic infarcts $[76,113-115]$, white matter microhemorrhages [113-115], microangiopathy [76], parenchymal hematomas [114], olfactory bulb abnormalities [114], and lymphohistiocytic inflammation [109]. Insights from imaging showcases perfusion abnormalities in cases of posterior reversible encephalopathy syndrome (PRES) will be discussed in more detail within the cardiovascular interactions section. Additionally, cerebrospinal fluid and plasma biomarker evidence support potential astrocytic injury and neuronal injury from COVID-19, but this evidence is nonspecific and only highlights that damage is indeed occurring [96]. Of those with neurological symptoms and subsequent cerebrospinal fluid testing, $40 \%$ had hyperproteinorrachia supporting inflammation or axonal injury [62]. Of clinical COVID-19 patients who received an MRI from altered mental status or focal weakness, neuroimaging studies showed that $22 \%$ of these patients have microbleeds and $26 \%$ have leukoencephalopathy [116]. Most of the microbleeds were found in subcortical white matter and the corpus callosum $[116,117]$ consistent with microbleed patterns observed in cases of hypoxemia and critical illness $[118,119]$. However, endotheliitis, kidney failure (through uremic toxins increasing BBB permeability), and thrombosis have also been theorized to be independent or compounding factors in COVID-19 microbleed formation $[117,118,120]$. In a group of 3-month recovered COVID-19 patients, neuroimaging demonstrated changes in both gray and white matter with few differences dependent on the severity level other than a decrease in global gray matter volume correlated with inflammation (lactate dehydrogenase levels) [121]. Gray matter increases across multiple regions occurred in these recovered COVID-19 patients including the olfactory cortices and hippocampus [121]. White matter changes, in general, were characterized by lower diffusivity and higher fractional anisotropy (with no differences in total white matter volume), indicating a potential remyelination [121]. Additionally, resting-state fMRI findings in individuals recovered from mild COVID-19 showed states of hyperconnectivity [122]. These neuroimaging findings demonstrate that structural brain changes are possible, even spanning across non-severe cases, but regardless, more imaging studies are necessary, including in recovered COVID-19 patients, to better quantify risk and potential long-term consequences.

\section{Cognitive Alterations and Long-Term Symptoms from} Clinical COVID-19 Survivors

Ultimately, one of the major concerns with a neurological viral influence is its subsequent impact on cognition. Overall, plausible cerebral injury from SARS-CoV-2 may induce or worsen cognitive impairment and dementia [46]. In particular, damage from hypoxia/ischemia, thromboemboli/stroke, and neuroinflammation, all possible from SARS-CoV-2 infection, are associated with cognitive decline and dementia [46]. While existing stud- 
Table 2. Rate estimations of long-term symptoms, loosely organized by frequency, from clinical patients recovered from acute features of COVID-19

Clinical COVID-19 survivor

$50 \%^{\dagger}[123], 76 \%^{\ddagger}[152]$
$71 \%^{\dagger}[153], 53 \%^{\ddagger}[152]$
$53 \%^{* *}[124], 28-53 \%^{\dagger}[123,125], 63 \%^{\ddagger}[152]$
$30-60 \%^{\dagger}[155,156]$
$57 \%^{\dagger}[128]$
$50 \%^{\dagger}[128]$
$28 \%^{* *}[127]$
$26 \%^{* *}[126], 33 \%^{\dagger}[128]$
$32 \%^{\dagger}[128]$
$8-40 \%^{* *}[126,127], 18 \%^{\dagger}[123], 26 \%^{\ddagger}[152]$
$21-31 \%^{* *}[126,127], 4.3 \%^{\dagger}[123], 23 \%^{\ddagger}[152]$
$18 \%^{* *}[126], 24 \%^{\dagger}[128]$
$21-58 \%^{\dagger}[123,158], 22-56 \%^{\ddagger}[152]$
$11 \%^{\dagger}[123]$
$57 \%^{*}[159]$
$31 \%^{*}[159]$
$*[160]$

Comparison population $\geq 1$ symptom

Chest CT abnormalities

Fatigue

Myocardial inflammation

Psychomotor coordination impairment

Executive function impairment

PTSD

Verbal fluency loss

Insomnia/sleep disturbance

Depression

Memory loss

Pulmonary function abnormalities

Resting heart rate increase

Hematuria (kidney)

Proteinuria (kidney)

Liver ALT, AST/ALT, GGT, and ALP levels
Loss of concentration
Comparison population

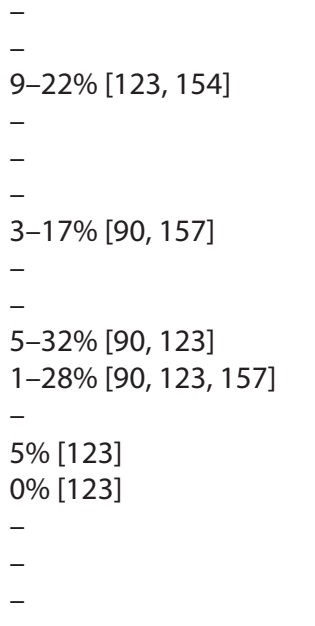

COVID-19, coronavirus disease 2019; CT, computed tomography; PTSD, posttraumatic stress disorder; ALT, alanine aminotransferase; AST, aspartate aminotransferase; GGT, $\gamma$-glutamyltransferase; ALP, alkaline phosphatase; SARS-CoV-2, severe acute respiratory syndrome coronavirus 2. A similar reference population is compared to disentangle the effects of the COVID-19 pandemic from SARS-CoV-2 infection. Only symptoms that could have a primary or a secondary effect on cognition are included. * Measurements at hospital discharge. ** Measurements at 1 month. ${ }^{\dagger}$ Measurements at 3 months. ${ }^{\ddagger}$ Measurement at 6 months.

ies are currently limited, immediate cognitive alterations were observed in patients recovered from COVID-19. Of note, the reported long-term cognitive decline spans several domains, including concentration, memory, executive function, psychomotor coordination, information processing, and language [123-128]. During the recovery phase of COVID-19, a middle-aged population, of various severity levels, experienced loss of sustained attention [129]. The degree of sustained attention alterations correlates with post-infection blood-based inflammatory levels [129]. Even within asymptomatic COVID-19 patients, cognitive deficits were observed in language and visuoperception, though there was no difference in overall cognitive ability from the control group [130]. The severity of COVID-19 disease state, from asymptomatic to requiring hospitalization, correlates with degree of cognitive changes [131]. The degree of cognitive changes can be consequential with hospitalized patients having between $0.45-0.57$ standard deviations of global cognitive performance loss compared with control populations [131]. Mostly relevant for higher severity COVID-19 patients, other aspects of COVID-19 such as development/ duration of delirium and ventilator treatment due to hypoxia can all contribute to long-term cognitive risk. Of clinical COVID-19 patients, 11-33\% develop delirium [79-81]. Of those admitted to the intensive care unit (ICU) from COVID-19 infection, up to $80 \%$ develop delirium at least once during their treatment [132]. Establishment of delirium and systemic inflammation, both present in severe and critically ill COVID-19 patients, is associated with future risk of dementia $[99,133,134]$. As supported in a recent meta-analysis, delirium development in clinical patients is an independent risk factor for long-term cognitive decline (up to $2.3 \times$ higher risk) [135]. Shown in populations initially free of cognitive impairment and across age, a longer duration of delirium can induce novel cognitive impairment at levels comparable to mild AD [136]. Patients who require ventilator treatment still often experience hypoxia; persistent dysfunction in attention, memory, language, processing speed, and executive functioning can occur in these patients for years after recovery [49]. Additionally, for those with pre-existing cognitive impairment, there is a greater risk for precipitous cognitive decline due to interactions between delirium and dementia [133, 137].

Other long-term effects of COVID-19, such as insomnia [138], chronic fatigue [139], social isolation [140], and development of psychological disorders such 
as posttraumatic stress disorder (PTSD) [141] and depression [142], can contribute to cognitive decline. As seen in Table 2, clinical COVID-19 survivors can experience long-term symptoms that may have primary or secondary effects on cognitive function. Long-term symptoms such as fatigue, cognitive alterations, myocardial inflammation, PTSD, insomnia, depression, pulmonary function abnormalities, resting heart rate increase, hematuria, proteinuria, and abnormal liver enzyme levels have all been reported in COVID-19 survivors. Of note, when compared with influenza or other respiratory tract infections, diagnosis rates of psychiatric illnesses, mood disorders, or anxiety disorders are higher after COVID-19 [143]. Often, recovered COVID-19 patients can have several of these long-term symptoms lasting at least 70 days with an unknown final duration [124, 125]. Additionally, as is the case for symptoms of fatigue, $\mathrm{CO}$ VID-19 severity does not always correspond with likelihood of developing long-term symptoms [125]. This observation is inconsistent with other post-viral fatigue syndromes, such as those attributed to brucellosis, glandular fever, and lyme disease, where disease severity correlates with the extent to which patients experience fatigue [144]. Even among ambulatory care COVID-19 patients, $35 \%$ have post-acute symptoms 16 days after COVID-19 testing, suggesting prolonged symptoms in non-severe cases [145]. In a sample of health care professionals with mild COVID-19 severity and seropositive testing, $26 \%$ reported $\geq 1$ long-term symptom after 2 months of recovery and $15 \%$ reported $\geq 1$ long-term symptom after 8 months of recovery [146]. For those with persistent long-term COVID-19 symptoms, termed "long-COVID," $13.3 \%$ of these individuals experience symptoms $>28$ days, $4.5 \%>56$ days, and $2.3 \%>84$ days [147] with neurological manifestations and fatigue being the most prominent in non-hospitalized individuals [148]. In general though, findings from other similar viral diseases suggest that cognitive alterations, psychological disorders, and long-term symptoms are all possible in COVID-19 patients. For example, recovered SARS patients reported long-term depression, insomnia, memory impairment, fatigue, and PTSD [149-151]. Other conditions such as sepsis, pneumonia, and acute respiratory distress syndrome can similarly increase risk for cognitive impairment and dementia in survivors [74, 150]. These conditions speak to the overall contribution of the body's organs in maintaining brain health, and, in the context of COVID-19, the health of the cardiovascular system likewise has implications for cognitive decline.

COVID-19 Dementia Risk

\section{Cardiovascular Interactions with COVID-19}

The cardiovascular system is intimately intertwined with neurological function and dementia risk. For example, heart disease, diabetes mellitus, hypertension/hypotension, hypercholesterolemia, obesity, lack of aerobic exercise, smoking [161, 162], stroke [163], and vascular damage [164] are well-documented risk factors for dementia. Of particular relevance to SARS-CoV-2, heart disease, risk for stroke, and vascular damage worsen in patients with moderate to severe cases of COVID-19. Additionally, SARS-CoV-2 disproportionately targets those with pre-existing cardiovascular risk factors, typically making cases more severe, and has the potential to compound pre-existing cardiovascular damage $[165,166]$. Injury to the cardiovascular system, from COVID-19, including myocardial, thromboemboli, and vascular damage could synergistically increase future dementia risk or exacerbate existing dementia.

In the case of heart disease, clinical COVID-19 can induce myocardial injury $(7-25 \%[77,167])$, myocardial infarction/shock (7-14\% [77, 82]), and arrhythmias (17\% [77]). Fifty-five percent of clinical patients, both with and without pre-existing cardiac disease, have an abnormal echocardiography feature in the left, right, or both ventricles to varying degrees of severity [168]. Even in asymptomatic and symptomatic college athletes, COVID-19 can induce subclinical pericardial (27\%), myocardial (17\%), and myopericardial (13\%) abnormalities, though appropriate control groups are needed to rule out athletic cardiac adaptation [169]. Similar to the viral pathway in the brain, the heart can have direct myocardial infection $[9,170]$, indirect damage from immune response, and/or ischemic damage [171]. Clinically, these pathways are difficult to disentangle, but non-specific cardiac biomarkers such as elevated troponin levels and ECG abnormalities are used to demonstrate cardiac damage $[167,171]$. Damage to the heart can take many forms including myocardial infarction, microinfarcts, ventricular fibrosis, and/or atrial fibrosis [171]. This damage can progress to cardiomyopathy, systolic/diastolic abnormalities, ventricular tachycardia, and atrial fibrillation [171]. Transthoracic echocardiography findings demonstrate that $35 \%$ of clinical COVID-19 patients have abnormal left ventricle wall motion and reduced ejection fraction ( $\leq 50 \%), 15 \%$ have increased right ventricle size, and $40 \%$ have decreased right ventricle systolic function [172]. In seemingly recovered COVID-19 patients, independent of infection severity level and comorbidities, $30-60 \%$ still have myocardial inflammation around 3 months after di-

Neurodegener Dis 2021;21:1-23 DOI: $10.1159 / 000518581$ 
agnosis $[155,156]$. In total, heart damage induced by COVID-19, both acute and chronic, can impair blood flow to the rest of the body including the flow-sensitive brain and in general is associated with risk for future cognitive impairment $[161,162]$.

In the case of stroke, clinical COVID-19 can induce macro/micro arterial/venous thromboemboli (4-7\% non-severe, $8-31 \%$ severe $[82,173-176])$ with acute cerebrovascular attack (0.5-1.4\% non-severe, $1.2-5.7 \%$ severe $[71-73,82])$ occurring as a subset. Additionally, in autopsy studies, it appears that deep vein thrombosis and pulmonary emboli can occur silently in clinical COVID-19 patients $[177,178]$, indicating that rates of thrombosis may be under-reported [173]. Importantly, abnormal coagulation parameters associated with thrombosis are highly linked with mortality in COVID-19 [179]. Coagulopathy manifests in a hypercoagulability/prothrombotic state to generate thrombi [176]. Typically, coagulopathy is defined as lower levels of platelets and increased D-dimer levels, prothrombin time, fibrinogen, factor VIII, and von Willebrand factor with D-dimer levels often used for disease prediction [176]. States of coagulopathy are documented in 19\% of clinical COVID-19 patients [180] and elevated rates of D-dimer are documented in $46 \%$ of patients [181]. From a causal standpoint, coagulopathy could be the result of infected cells generating proinflammatory cytokines or hypoxic conditions [177, 182]. While the dangers of macro-thromboemboli are clear and present, the rates of micro-thromboemboli would be more difficult to detect clinically and may have long-term consequences. In further autopsy studies, microscopic thrombi are found in $80-100 \%$ of lungs [182], opening the possibility that micro-thromboemboli are traveling to other organs, including the brain, in severe COVID-19 patients. From MRI scans of COVID-19 patients, non-confluent multifocal white matter hyperintensities on fluid-attenuated inversion recovery and diffusion-weighted imaging have been found [115]. Similar patterns were observed following transcatheter aortic valve implantation that may result in long-term suboptimal cognitive outcomes [183]. Additionally, if present, micro-thromboemboli may contribute to coronary dysfunction [171] as well as damage to other organs. More studies are needed to determine if micro-thromboemboli or subclinical thromboemboli are present in milder cases of COVID-19.

In the case of vascular damage, the potential for COVID-19 to do lasting damage derives from endothelial cell injury after direct viral infection (shown systemically in SARS-CoV-2-infected organs [184]) or immune-mediat- ed inflammation. Endothelial cell injury can contribute to the dysregulation of the renin-angiotensin-aldosterone system, which partially controls arterial blood pressure fluctuations and cerebral blood flow. With impaired endothelial cells, the regulation of vascular tone (autoregulation) is disrupted and thus higher fluctuations of blood pressure and cerebral blood flow occur. With SARSCoV-2 decreasing the bioavailability of ACE2 receptors, vasoconstriction and hypertension tend to increase. PRES is a possible consequence of endothelial cell dysfunction and/or hypertension where autoregulation compensation abilities cannot control cerebral blood flow adequately [185]. Thus, symptoms of PRES can manifest as either cerebral hypoperfusion or hyperperfusion [185]. The reason why these seemingly opposite flow manifestations can occur is potentially explained by the timeline of disease progression [186]. As uncontrolled hypertension increases, possible in COVID-19 as the renin-angiotensin-aldosterone system is disrupted, autoregulatory mechanisms compensate with vasoconstriction that results in cerebral hypoperfusion. Then, as endothelial cell dysfunction continuously weakens autoregulation abilities and hypertension increases, autoregulatory mechanisms eventually reach their maximum vasoconstriction abilities, resulting in cerebral hyperperfusion. In a preprint publication, PRES is listed as a possible COVID-19 manifestation shown by 25 patients clinically presenting with PRES in both the hypoperfusion and hyperperfusion progression stages [187]. PRES has also been observed in other COVID-19 patient populations to varying degrees $[113,188]$. Hypoperfusion and flow disruptions are especially damaging to cerebral white matter; notably, a majority of $\mathrm{AD}$ patients manifest with white matter hyperintensities, suggestive of similar ischemic damage [46]. Perfusion abnormalities within small cerebral blood vessels, in the context of COVID-19, are primarily attributed to a decrease in endothelial cells due to a loss of vascular wall adhesion [189]. Endothelial cell dysfunction, similar to the effects of hypoperfusion, could lead to decreased clearance of cerebral metabolites such as amyloid beta and has been implicated in tau formation [46]. Disruptions to endothelial cells, in the form of endotheliitis, could also be implicated in the origins of cerebral microbleeds, especially in COVID-19 patients diagnosed with encephalopathy [190]. In addition to endothelial dysfunction, vascular damage could take the form of impaired baroreflex that would risk the ability of the body to respond to dynamic blood pressure needs [191] as well as chronic atherosclerosis [192]. Evidence from young adults 3-4 weeks after mild COVID-19 recovery indicate
Pyne/Brickman 
systemic vascular alterations in the form of increased vascular stiffness, measured through pulse wave velocity, and decreased flow-mediated dilation in the arm [193]. This vascular evidence across mild to severe COVID-19 patients indicates that perfusion abnormalities and endothelial/vascular dysfunction can occur in both the systemic and cerebral cardiovascular system with risk for cognitive decline.

\section{Pulmonary, Renal, and Liver Interactions with COVID-19}

In addition to the cardiovascular system, damage to other organ systems by COVID-19 can potentially increase risk for future cognitive decline. For example, damage to the pulmonary system, renal dysfunction [162, 194], and liver dysfunction $[195,196]$ can increase dementia risk or affect dementia progression. For the pulmonary, renal, and hepatic systems, SARS-CoV-2 can directly infect these organs, indirectly damage them from systemic inflammatory response, and/or induce thromboembolic damage $[197,198]$. Analogous to the brain and cardiovascular system, downregulation of ACE2 due to the SARS-CoV-2 attachment plays a critical role in COVID-19 pathogenesis. ACE2 levels are a critically important aspect of pulmonary protection against damage [17, 199]. This also holds true for the kidneys, where decreases in ACE2 expression can compound renal damage [200]. Across COVID-19 severity, damage to these organ systems has been observed to varying degrees ultimately presenting as increased risk for future cognitive decline.

One of the most consistent clinical signs of COVID-19 includes a cough that could be indicative of pneumonia, diagnosed through chest computed tomography (CT) evaluation. Ground glass opacity areas can be seen broadly in the lungs, from CT imaging, in up to $98 \%$ of patients throughout infection [201]. Many other virus-associated changes are commonly observed in the lungs, including consolidation, reticulation, air bronchogram, and vascular enlargement [201]. Physical pulmonary abnormalities occur even in patients presenting with asymptomatic and mild COVID-19 cases, including young children [202, 203]. While asymptomatic cases have a lower presentation of pulmonary abnormalities than symptomatic COVID-19 patients, the percentage is still high at 49\% [202]. At the extreme, one of the most serious forms of pulmonary dysfunction is acute respiratory distress syndrome (ARDS). This syndrome is diagnosed when arterial blood oxygen levels are low enough to induce hypoxia. About
$33 \%$ of hospitalized COVID-19 patients experience ARDS, with many needing ICU or ventilator treatment [204]. Additionally, 30\% of clinical patients experience COVID-19-induced acute pulmonary embolism [205]. In autopsy results, the type of pulmonary damage present primarily takes the form of diffuse alveolar damage across a large majority of cases [206, 207]. Additionally, macrovascular (42\%), but especially microvascular (84\%), thromboemboli were present in autopsied lungs [206]. This type of damage to the lungs is consistent with systemic hypoxia, known to be associated with a wide range of outcomes such as an increase in inflammatory factors as well as increased blood coagulation [208, 209]. For the brain, hypoxia can induce neuronal injury/loss through disruption of cerebral homeostasis. As oxygen levels decrease in the brain, rising carbon dioxide levels results in an acidosis that, at extreme levels, will induce vasospasm and vascular permeability. Ultimately, this cascade could result in neuronal and astroglial injury/death that will present as cognitive decline [208]. As worsening pulmonary health is correlated with neurological symptoms in COVID-19 patients, the hypoxia cascade is a plausible component of detrimental neurological alterations [210]. Fibrosis is a possible long-term pulmonary consequence from COVID-19, especially after long-duration severe disease, which can reduce overall lung capacity and reduce the efficiency of gas exchange [211]. In recovered clinical COVID-19 patients with no pre-existing pulmonary comorbidities, long-term pulmonary alterations have been observed after 3 months [153]. Of the recovered patients, who mostly comprised of moderate COVID-19 severity, 71\% had abnormalities on chest CT scans with $31 \%$ of those with CT abnormalities manifesting as noticeable pulmonary abnormalities [153]. Even within the group without CT abnormalities, some individuals experienced pulmonary abnormalities, suggesting that sub-imaging damage can occur [153]. In cases of similar pulmonary damage from SARS-CoV-1 and influenza A, full recovery could take years [212]. Ultimately, chronic pulmonary damage from COVID-19 may increase risk of future cognitive impairment as similar to chronic hypoxemia, chronic obstructive pulmonary disease, and obstructive sleep apnea [213]. In severe COVID-19 cases, the possibility of future cognitive impairment is even higher based on reports of patients with ARDS who develop cerebral atrophy, ventricular enlargement, and cognitive alterations $[49,214]$.

Kidney damage is also common in COVID-19 and pre-existing kidney damage represents a mortality risk factor. Across the broad spectrum of clinical COVID-19 
patients, $44-75 \%$ presented with abnormal kidney function [215], which could be signs of kidney damage, both in the form of blood in urine (hematuria: $42 \%$ ) and high levels of protein in urine (proteinuria: 66\%) [159]. Of note, these COVID-19 rates of hematuria and proteinuria are similar to rates present from other critical illness [159]. In non-severe patients, acute kidney injury (AKI) was observed in about $2 \%$ of clinical patients, but severe patients had much higher rates at $19-37 \%$ [215, 216]. For those with more serious AKI, about $20 \%$ of the severe patients, renal replacement therapy such as dialysis is required [217]. Autopsy studies showed kidney damage, with the primary form being acute tubular injury/necrosis $[159,197,218]$. While long-term data regarding kidney damage are still necessary, information from hospital discharge can give some insight into expected recovery rates. For example, of the discharged clinical COVID-19 patients who experienced renal dysfunction, $69 \%$ had proteinuria recovery and $43 \%$ had hematuria recovery [159]. Of patients with AKI, only $18 \%$ fully recovered by hospital discharge [159]. For those who required renal replacement therapy (associated with severe AKI) and survived COVID-19, 33\% remain dependent on renal replacement therapy at discharge with $17 \%$ remaining dependent after 60 days [217]. As in other diseases cases of AKI, the progression to chronic kidney disease could be as high as $25 \%$, demonstrating long-term damage potential [219]. Renal damage, beyond the direct dysfunctional effect, could interact synergistically with cardiovascular abnormalities resulting in further myocardial dysfunction [191]. AKI has the potential to accumulate nitrogenous waste in the brain, disrupt cerebral osmolality, and promote cerebral inflammation [220]. These alterations can disrupt the permeability of the BBB [220]. The renal injury effects can influence multiple brain regions, but the hippocampus appears to be particularly susceptible [220]. Ultimately, the culmination of long-term renal damage, due to COVID-19, presents a cognitive impairment risk to survivors $[162,194]$.

For COVID-19, liver abnormalities in the form of elevated enzyme levels occur across the spectrum of disease severity. For example, $18-21 \%$ and $21-22 \%$ of clinical COVID-19 patients have elevated alanine aminotransferase (ALT) and aspartate aminotransferase, respectively $[181,221]$. Other potential markers of injury include $\gamma$-glutamyltransferase (11-21\%), total bilirubin (6-35\%), and alkaline phosphatase (4-6\%) with $16-53 \%$ of total hospitalized COVID-19 patients experiencing abnormal liver function [181, 221-223]. Overall, worse COVID-19 severity correlates with higher levels of liver abnormali- ties [224, 225]. With severe COVID-19 cases, liver abnormalities can progress to acute liver injury in $5-6 \%$ of clinical COVID-19 patients [224, 225]. In terms of pathological damage, injury can take the form of micro- and macrovesicular steatosis as well as dysfunction of intrahepatic portal vein branches, mild lobular and portal inflammation, ductular proliferation, and cellular necrosis [222]. As mentioned, organ damage can have a number of plausible origins, but for the liver specifically, hepatotoxic drug-induced injury from various treatment options is an additional possibility [197]. Within 14 days of hospital discharge, ALT, alkaline phosphatase, aspartate aminotransferase/ALT, $\gamma$-glutamyltransferase, and other liver enzyme levels remained abnormal in recovered COVID-19 patients, compared with controls [160]. While overall liver enzymes trended toward recovery over 40 days in these patients, not all enzymes fully normalized making the complete recovery timeline unknown [160]. These enzyme trends are supported by abnormal plasma metabolic profiles, after 3 months of recovery time, which could indicate prolonged liver injury [226]. While the complete long-term implications of abnormal liver function are not yet known and additional follow-up data are needed, warning signs of liver injury exist in recovered COVID-19 patients that could contribute to dementia risk $[195,196]$.

\section{Aging Complications}

With the viral mechanisms and major damage pathways to COVID-19-induced cognitive decline risk delineated, certain groups, such as older adults, are at greater risk for severe COVID-19 and subsequent cognitive decline. Advancing age is the strongest independent risk factor for COVID-19-related severe illness and death, with extreme risk for those above 80 years old $[3,227]$. This disproportional mortality is extreme; $94-99 \%$ of patients who died from COVID-19 were older than 50 years old $[228,229]$. While pre-existing comorbidities for the elderly, relevant for $35-66 \%$ of those above 65 years of age [230], can increase the severity and mortality risk of COVID-19, age alone still exists as an independent risk factor for heightened COVID-19 severity. On the other end of the age spectrum, children, though not free of COVID-19 symptoms or mortality [231], most often experience asymptomatic or mild symptoms from COVID-19 [232]. It is those of older age who are at greatest risk for dementia [233]; thus, it is important to examine how COVID-19 might modulate this risk. There are multiple
12

Neurodegener Dis 2021;21:1-23 DOI: $10.1159 / 000518581$
Pyne/Brickman 
contributing factors that could explain this steep gradient in age-related COVID-19 response, including changes in ACE2 expression, immune response, and systemic frailty.

Starting with ACE2 levels, the attachment point for SARS-CoV-2, the mechanism of limited ACE2 bioavailability could influence response severity to the virus [18]. Similar to those with pre-existing ACE2 deficiencies such as individuals with hypertension and diabetes mellitus, those of older age experience a decrease in ACE2 bioavailability, leading to increased risk of organ injury. Overall, adults can have lower systemic ACE2 expression than children [234] as well as lower circulating ACE2 levels [235]. For vascular considerations, based on mice experiments, ACE2 expression steadily decreases with age [236]. In the brain specifically, where ACE2 levels influence blood pressure control and autoregulation [41, 42], there is an age-dependent component where ACE2 levels are more critical for older adults. For example, in mouse models with ischemic injury, higher ACE2 levels are considered to be protective against damage with those of older age experiencing the most benefit [44]. For cases of COVID-19, where ACE2 receptors are being taken up by the SARS-CoV-2 virus in a lower bioavailability state due to aging, acute exasperation of these negative vascular effects could affect neurological symptoms.

To effectively battle SARS-CoV-2, the body's immune system must recognize the viral threat, signal the proper immune cells, destroy the virus, and clear the debris [237]. As the body ages, the immune system undergoes alterations in the form of immunosenescence and inflammaging [237]. Immunosenescence, the decline of recognition, signaling, and clearance abilities of both the innate and adaptive immune systems have implications for viral defense [237-239]. Likewise, inflammaging (chronic, systemic, and low-grade inflammation) occurs as part of the aging process through a disrupted inflammation balance that increases an individual's viral susceptibility [240]. Overall, these age-related changes in the immune system allow for greater viral replication due to delayed alerting and an overactive immune response that could result in a detrimental cytokine storm [237]. Observations in differing antibody profiles between adults and children with COVID-19 show that children have the ability to clear the SARS-CoV-2 infection faster with a less powerful immune response protecting them from an excessive immune reaction [241]. Overall, while there are multiple aspects to the aged immune system interaction with SARSCoV-2 [237, 242], immune response and development to cytokine storm are among the most important factors in an individual's outcome to COVID-19 and neurological symptoms [35].

As a common part of aging, systemic frailty influences multiple aspects of the body that play an essential role in fighting off SARS-CoV-2 infection. While the definition of frailty is not always robustly defined in the elderly, it is considered distinct from comorbidities and disability, though there can be a significant overlap [230, 243]. Frailty stems primarily from the culmination of multiple nonoptimally operating organ systems and lack of robustness in maintaining homeostasis $[230,244]$ derived from both biological and pathophysiological sources [245]. Ultimately, with relevance for COVID-19 illness, frailty leads to reduced mechanical advantage, atypical presentation, and the comorbidity of pulmonary disease in the elderly [239]. For reduced mechanical advantage, weakening of thorax muscles paired with increased stiffness of lung structures can diminish oxygen uptake through limited gas exchange across a reduced pulmonary reserve, as well as impair cough strength, thus reducing possible clearance of viral particles $[239,246]$. Those who are frail, independent of age and comorbidities, are at greater risk for severe COVID-19 and mortality [243, 247-249]. In fact, frailty status can be a better predictor of COVID-19 response than age or comorbidity alone, depending on the scale utilized [248].

\section{Disparities}

While advancing age is the biggest predictor of COVID-19 severity, disparities in COVID-19 severity and outcome have been observed across both sex and race/ ethnicity in the USA. Independent of age and with similar infection rates, men are more likely to have severe COVID-19 that requires admissions to ICUs [227, 250, 251] and a higher fatality rate than women, with men making up approximately $70-75 \%$ of COVID-19 deaths [166, $228,250]$. In the USA, Black Americans, Hispanic/Latinx, and American Indian populations have been disproportionately affected by COVID-19 compared with non-Hispanic White populations. For Black Americans, the risk of SARS-CoV-2 infection is 3 times higher than non-Hispanic White populations [252]. This stark disproportion leads to Black Americans comprising 34\% of the COVID-19 mortality rate while only representing $13 \%$ of the USA population [253]. Hispanic/Latinx populations, within the USA, make up $28 \%$ of the COVID-19 cases while only comprising $18 \%$ of the general population [254]. Ultimately, based on New York City estimations, 
Hispanic/Latinx populations have twice the risk of COVID-19 mortality compared to non-Hispanic White populations [254]. Pooled across 23 states, American Indians and Alaskan Native persons experience 3.5 times more SARS-CoV-2 infections than non-Hispanic White populations [255]. While overall mortality across these states is not fully documented [255], using Arizona as an example, $18 \%$ of the COVID-19 deaths are of American Indians while only comprising $5.3 \%$ of the state's population [256]. Importantly, sex differences in COVID-19 response appear to stem from biological causes, while, in our opinion, racial/ethnic differences are primarily the result of systemic racism.

Parsing through sex disparities in COVID-19 response includes the main factors of ACE2 expression and immune system differences. Regarding ACE2 expression, women generally have higher levels of ACE2 expression overall [234], though this has been contested [20]. Additionally, women have a less dramatic decrease in ACE2 expression with age compared with men [234]. The higher ACE2 expression in women could be the result of increased estrogen levels, which may reduce COVID-19-related organ damage via relatively higher levels of systemic ACE2 availability [234, 235]. In general, women and men have sexual dimorphism in immune response that could interact with ACE2 expression [257, 258]. Typically, women mount stronger immune responses to pathogens [258], but higher ACE2 levels can dampen this immune response in the context of COVID-19 [20]. For example, in the lungs, higher ACE2 levels in SARS-CoV-2-infected women correlated with a lower immune response, whereas lower ACE2 levels in men correlated with stronger immune response and increased risk of cytokine storm [20]. Lastly, COVID-19 interactions with pre-existing comorbidities stratified by sex may influence outcome, but more data are needed [259].

With respect to racial/ethnic differences in SARSCoV-2 infection response, there is little supporting evidence of biological differences between groups that influence outcomes. When controlling for comorbidities, no differences in ACE2 levels exist across race [20]. Once including cardiovascular and pulmonary comorbidities, differences in ACE2 polymorphisms could account for aspects of increased COVID-19 susceptibility [260]. In addition, differences in nasal TMPRSS2 levels could be influential in COVID-19 infection risk [261]. Notably, cardiovascular disease and gene expression (ACE2 and TMPRSS2) differences across race are influenced by social and environmental factors (also known as social determinants of health) $[262,263]$. In the USA, Black, His-
panic/Latinx, and American Indian populations have higher rates of vascular risk factors such as hypertension, diabetes, and obesity [264] compared with non-Hispanic White populations. These differences are mediated by reduced medical access, limited resources, discrimination, and other social determinants of health across the lifetime and may interact to increase dementia risk in certain groups [265]. Higher rates of COVID-19 exposure due to in-person work and household exposure increase the infection potential $[253,256]$. In the context of COVID-19, Black Americans, Hispanic/Latinx, and American Indian populations have a greater pre-existing risk of cognitive decline that is now potentially compounded with disproportionate rates and more severe cases of COVID-19. This occurrence of higher rates and more severe cases within marginalized populations is consistent with previous disease outbreaks, such as in the H1N1 influenza A pandemic and seasonal influenza [266]. Ultimately, more access to medical care, health insurance options, societal support, and vaccine access need to be distributed to Black Americans, Hispanic/Latinx, and American Indian populations disproportionally battling the COVID-19 pandemic.

\section{Implications for Dementia}

Overall, SARS-CoV-2 infection, moderated in severity by age-, sex-, and race/ethnicity-dependent factors, initiates a disease progression that has the potential to promote cognitive decline and exacerbate pre-existing dementia (see Fig. 1). The damage cascade of COVID-19 is multifaceted and interdependent, with multiple pathways that could lead to cognitive hazard mechanisms. One such cognitive hazard mechanism, cerebral direct infection, is possible with the SARS-CoV-2 virus, exhibiting neuroinvasive and neurotropic characteristics with neurovirulent potential. The greatest cognitive risk though may be from immune-mediated damage originating as cytokine storms that have far-reaching consequences for multiple organ systems, including the brain. Damage to organ systems and detrimental immune response, across the disease progression of COVID-19, may affect cognition via cerebral ischemia, hypoxia/acidosis, and neuroinflammation. The initiation of a coagulation cascade, from excessive immune response, which can generate micro-/macro-thromboemboli also poses significant risk. While long-term cognitive outcomes have not been fully evaluated, emerging reports indicate high rates of longterm symptoms and cognitive alterations in recovered
Pyne/Brickman 


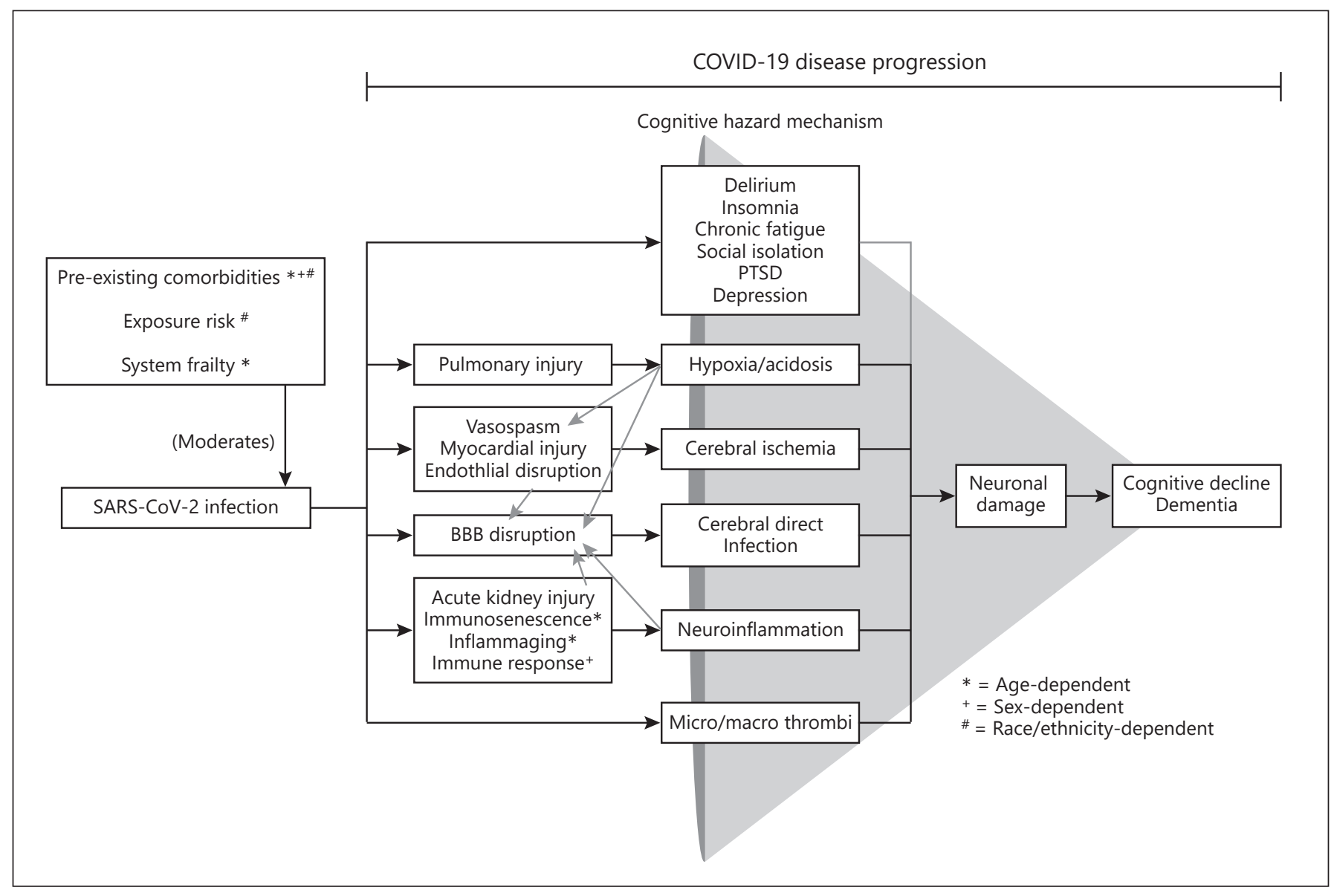

Fig. 1. SARS-CoV-2 infection, with age-, sex-, and race/ethnicity-dependent moderators that influence severity, initiates interdependent damage pathways that have the potential to cascade toward the outcome consequence of long-term cognitive decline and/or dementia. Lighter gray arrows represent conditional influences. SARSCoV-2, severe acute respiratory syndrome coronavirus 2; PTSD, posttraumatic stress disorder; COVID-19, coronavirus disease 2019.

COVID-19 patients. Due to these plausible COVID-19 cognitive decline pathways, evidence of prevalent neurological symptoms in patients, and long-term symptoms in recovered individuals, our conclusion is that COVID-19 represents a credible risk for cognitive decline and has the potential to exacerbate pre-existing dementia. For those at higher baseline dementia risk, older adults, those with cardiovascular risk factors, and people of color, COVID-19 may not only increase the risk of cognitive decline but also interact in a synergistic way with preexisting dementia risk factors to disproportionately increase this dementia risk.

For those with severe COVID-19 or cases of long-term symptoms, there are limited evidence-based interventions that address cognitive decline or risk of future decline. While long-term studies on the effectiveness of re- covery therapies have not yet been evaluated, strategies based on the medical needs of recovered critically ill COVID-19 patients and past recovery experience from patients with sepsis may provide some guidance [150,267]. For example, recovering COVID-19 patients may benefit from adhering to structured exercise programs, attending physical/occupational therapy, optimizing nutrition, reducing existing cardiovascular risk factors, practicing proper sleep hygiene, seeking out peer support [268], attending cognitive therapy/training, and seeking mental health support [150, 267]. Clinicians should be aware of the possibility of risk for cognitive decline or persistence of cognitive symptoms and monitor cognitive health closely, seeking formal neuropsychological evaluation when indicated [267]. In addition, patient reports indicate the need for follow-up appointments, the review/op- 
timization of medication on a regular basis, facilitation of referrals to specialists, education on respiratory treatments, and coordination across health services and between providers $[150,267]$. When possible, early rehabilitation after complete recovery, or especially during hospitalization, is shown to be more beneficial in COVID-19 patients than later [267]. Together, these suggestions may help mitigate the effect of COVID-19 on longterm symptom outcomes.

There is an essential need for longitudinal studies that include recovered COVID-19 patients to evaluate longterm symptoms, measure organ damage where possible, and perform cognitive outcome measures [49]. To quantify the viral effects properly, populations of interest should include all ranges of COVID-19 severity from asymptomatic to severe patients as well as broad age ranges. Of critical importance is the inclusion of underrepresented populations as well as non-hospitalized individuals who had COVID-19. Cases of multiple infection and long-COVID will also be important for understanding mechanisms potentially linking COVID-19 to cognitive decline [269]. Longitudinal studies should ideally include neuroimaging to track potential cerebral structural, functional, and cerebrovascular consequences of infection. For existing studies about cognitive aging and dementia, it will be important to collect participant information related to COVID-19 [49]. Other critical topics include quantifying the persistence of SARS-CoV-2 in the brain to understand potential neurovirulence effects and fully identifying its role in potential neuropathogenesis [47].

In the USA, the COVID-19 pandemic has disproportionately affected minoritized communities. With both higher infection rates and more severe outcomes, these populations have endured the brunt effects of COVID-19 in a multifaceted way. The amplified influence of COVID-19 in these populations could be mitigated through improved medical access, food security, job-based personal protective equipment, housing availability, financial assistance, and better public health initiatives to increase trust $[266,270]$. COVID-19 is unlikely to be the world's last coronavirus outbreak, so creating robust systems for health equality to prevent this type of damage to our communities is essential moving forward [49].

Based on the availability of current data, we can make predictions about how many individuals are at risk for dementia progression. To establish a baseline percentage of COVID-19 severity across cases, the largest recorded population of 44,000 COVID-19 cases from the Chinese Center for Disease Control and Prevention indicates that $\approx 80 \%$ of COVID-19 cases are asymptomatic/mild, $\approx 14 \%$ severe, and $\approx 5 \%$ critically ill [271]. If all severe COVID-19 cases are considered to be at risk for cognitive decline from infection, then to date, an additional 4.7 million individuals within the USA and 26 million people worldwide would be at risk [1]. While the death rate of COVID-19 is high, the long-term health consequences of those recovering from COVID-19 should not be understated or ignored [272]. These numbers represent an alarming clinical case load for extended COVID-19 monitoring, a significant challenge, but essential for full population recovery.

\section{Conflict of Interest Statement}

In the past 3 years, Dr. Brickman has received paid compensation for consultation or advisory activities to Regeneron Pharmaceuticals, F. Hoffmann-La Roche Ltd., Cognition Therapeutics, Inc., and Albert Einstein College of Medicine. He owns stock in Venus Medtech via Mars Holding Company. Dr. Brickman has a US patent (US9867566B2) and a patent pending (US20180228422A1), and has a copyrighted neuropsychological test instrument. His work has been supported by the US National Institutes of Health and Mars Symbioscience.

\section{Funding Sources}

This work was supported in part by Grant P30 AG066462 from the US National Institutes of Health/National Institute on Aging.

\section{Author Contributions}

J.D.P. drafted the manuscript. A.M.B. and J.D.P. worked together to craft the hypothesis, critique the manuscript, tables, and figure, and approve the final manuscript.
References

Neurodegener Dis 2021;21:1-23 DOI: $10.1159 / 000518581$
1 Dong E, Du H, Gardner L. An interactive web-based dashboard to track covid-19 in real time. Lancet Infect Dis. 2020;20(5):533-4.

2 van Oosterhout C, Hall N, Ly H, Tyler KM. COVID-19 evolution during the pandemic: implications of new SARS-CoV-2 variants on disease control and public health policies. Virulence. 2021;12(1):507-8.

3 Williamson EJ, Walker AJ, Bhaskaran K, Bacon S, Bates C, Morton CE, et al. Factors associated with covid-19-related death using opensafely. Nature. 2020;584(7821):430-6.

4 Kivipelto M, Ngandu T, Laatikainen T, Winblad B, Soininen H, Tuomilehto J. Risk score for the prediction of dementia risk in 20 years among middle aged people: a longitudinal, population-based study. Lancet Neurol. 2006; 5(9):735-41.
16 
5 Li H, Wang Y, Ji M, Pei F, Zhao Q, Zhou Y, et al. Transmission routes analysis of SARSCOV-2: a systematic review and case report. Front Cell Dev Biol. 2020;8:618.

6 Zhang H, Zhou P, Wei Y, Yue H, Wang Y, Hu $M$, et al. Histopathologic Changes and SARSCoV-2 immunostaining in the lung of a patient with COVID-19. Ann Intern Med. 2020; 172(9):629-32.

7 Wang C, Cai J, Chen R, Shi Z, Bian X, Xie J, et al. Aveolar macrophage activation and cytokine storm in the pathogenesis of severe covid-19. Res Sq. 2020.

8 Paniz-Mondolfi A, Bryce C, Grimes Z, Gordon RE, Reidy J, Lednicky J, et al. Central nervous system involvement by severe acute respiratory syndrome coronavirus-2 (sarscov-2). J Med Virol. 2020;92(7):699-702.

9 Tavazzi G, Pellegrini C, Maurelli M, Belliato M, Sciutti F, Bottazzi A, et al. Myocardial localization of coronavirus in covid-19 cardiogenic shock. Eur J Heart Fail. 2020;22(5):9115.

10 Diao B, Wang C, Wang R, Feng Z, Zhang J, Yang $\mathrm{H}$, et al. Human kidney is a target for novel severe acute respiratory syndrome coronavirus 2 infection. Nat Commun. 2021; 12(1):2506-9.

11 Wang Y, Liu S, Liu H, Li W, Lin F, Jiang L, et al. Sars-cov-2 infection of the liver directly contributes to hepatic impairment in patients with covid-19. J Hepatol. 2020;73(4):807-16.

12 Moriguchi T, Harii N, Goto J, Harada D, Sugawara $\mathrm{H}$, Takamino J, et al. A first case of meningitis/encephalitis associated with sarscoronavirus-2. Int J Infect Dis. 2020;94:55-8.

13 Huang YH, Jiang D, Huang JT. Sars-cov-2 detected in cerebrospinal fluid by pcr in a case of covid-19 encephalitis. Brain Behav Immun. 2020;87:149.

14 Feng Z, Diao B, Wang R, Wang G, Wang C, Tan $\mathrm{Y}$, et al. The novel severe acute respiratory syndrome coronavirus 2 (sars-cov-2) directly decimates human spleens and lymph nodes. medRxiv. 2020.

15 Robba C, Battaglini D, Pelosi P, Rocco PRM. Multiple organ dysfunction in sars-cov-2: Mods-cov-2. Expert Rev Respir Med. 2020; 14(9):865-8.

16 Gheblawi M, Wang K, Viveiros A, Nguyen Q, Zhong JC, Turner AJ, et al. Angiotensin-converting enzyme 2: Sars-cov-2 receptor and regulator of the renin-angiotensin system: celebrating the 20th anniversary of the discovery of ace2. Circ Res. 2020;126(10):145674.

17 Kuba K, Imai Y, Ohto-Nakanishi T, Penninger JM. Trilogy of ACE2: a peptidase in the renin-angiotensin system, a sars receptor, and a partner for amino acid transporters. Pharmacol Ther. 2010;128(1):119-28.

18 Verdecchia P, Cavallini C, Spanevello A, Angeli F. The pivotal link between ACE2 deficiency and SARS-COV-2 infection. Eur J Intern Med. 2020;76:14-20.

19 South AM, Diz DI, Chappell MC. Covid-19, ace2, and the cardiovascular consequences.
Am J Physiol Heart Circ Physiol. 2020;318(5): H1084-90.

20 Li MY, Li L, Zhang Y, Wang XS. Expression of the sars-cov- 2 cell receptor gene ace 2 in a wide variety of human tissues. Infect Dis Poverty. 2020;9(1):45-7.

21 Uhlén M, Fagerberg L, Hallström BM, Lindskog C, Oksvold P, Mardinoglu A, et al. Tissue-based map of the human proteome. Science. 2015;347(6220):1260419.

22 Kumar A, Pareek V, Prasoon P, Faiq MA, Kumar P, Kumari C, et al. Possible routes of sarscov-2 invasion in brain: in context of neurological symptoms in covid-19 patients. J Neurosci Res. 2020;98(12):2376-83.

23 Mönkemüller K, Fry L, Rickes S. Covid-19, coronavirus, sars-cov-2 and the small bowel. Rev Esp Enferm Dig. 2020;112(5):383-8.

24 Shang J, Wan Y, Luo C, Ye G, Geng Q, Auerbach A, et al. Cell entry mechanisms of sarscov-2. Proc Natl Acad Sci U S A. 2020;117(21): 11727-34.

25 Cantuti-Castelvetri L, Ojha R, Pedro LD, Djannatian M, Franz J, Kuivanen S, et al. Neuropilin-1 facilitates sars-cov-2 cell entry and infectivity. Science. 2020;370(6518):85660.

26 Daly JL, Simonetti B, Klein K, Chen KE, Williamson MK, Antón-Plágaro C, et al. Neuropilin-1 is a host factor for sars-cov-2 infection. Science. 2020;370(6518):861-5.

27 Wicik Z, Eyileten C, Jakubik D, Simões SN, Martins DC, Pavão R, et al. Ace2 interaction networks in covid-19: a physiological framework for prediction of outcome in patients with cardiovascular risk factors. J Clin Med. 2020;9(11):3743.

28 Lechien JR, Radulesco T, Calvo-Henriquez C, Chiesa-Estomba CM, Hans S, Barillari MR, et al. Ace2 \& tmprss2 expressions in head \& neck tissues: a systematic review. Head Neck Pathol. 2021;15(1):225-235.

29 Barbry P, Muus C, Luecken M, Eraslan G, Waghray A, Heimberg G, et al. Integrated analyses of single-cell atlases reveal age, gender, and smoking status associations with cell type-specific expression of mediators of sarscov-2 viral entry and highlights inflammatory programs in putative target cells. bioRxiv. 2020.

30 Mayi BS, Leibowitz JA, Woods AT, Ammon KA, Liu AE, Raja A. The role of neuropilin-1 in covid-19. PLoS Pathog. 2021;17(1): e1009153.

31 Ocaranza MP, Jalil JE. Protective role of the ace2/ang-(1-9) axis in cardiovascular remodeling. Int J Hypertens. 2012;2012:594361.

32 Chiappelli F. Towards neuro-covid-19. Bioinformation. 2020;16(4):288-92.

33 Zores F, Rebeaud ME. Covid and the reninangiotensin system: are hypertension or its treatments deleterious? Front Cardiovasc Med. 2020;7:71.

34 Turner AJ. Chapter 25 ace 2 cell biology, regulation, and physiological functions. In Unger T, Steckelings UM, dos Santos RA, editors. The protective arm of the renin angiotensin system (RAS). Boston: Academic Press; 2015. p. $185-189$.

35 Fajgenbaum DC, June CH. Cytokine storm. N Engl J Med. 2020;383(23):2255-73.

36 Offringa A, Montijn R, Singh S, Paul M, Pinto YM, Pinto-Sietsma S-J. The mechanistic overview of sars-cov-2 using angiotensinconverting enzyme 2 to enter the cell for replication: possible treatment options related to the renin-angiotensin system. Eur Heart J Cardiovasc Pharmacother. 2020;6(5):317-25.

37 Imai Y, Kuba K, Rao S, Huan Y, Guo F, Guan $B$, et al. Angiotensin-converting enzyme 2 protects from severe acute lung failure. $\mathrm{Na}-$ ture. 2005;436(7047):112-6.

38 AlGhatrif M, Cingolani O, Lakatta EG. The dilemma of coronavirus disease 2019, aging, and cardiovascular disease: insights from cardiovascular aging science. JAMA Cardiol. 2020;5(7):747-8.

39 Li G, He X, Zhang L, Ran Q, Wang J, Xiong A, et al. Assessing ace 2 expression patterns in lung tissues in the pathogenesis of covid-19. J Autoimmun. 2020;112:102463.

40 Ziegler CGK, Allon SJ, Nyquist SK, Mbano IM, Miao VN, Tzouanas CN, et al. Sars-cov-2 receptor ace 2 is an interferon-stimulated gene in human airway epithelial cells and is detected in specific cell subsets across tissues. Cell. 2020;181(5):1016-35.e19.

$41 \mathrm{Xia} \mathrm{H}$, Lazartigues E. Angiotensin-converting enzyme 2 in the brain: properties and future directions. J Neurochem. 2008;107(6):148294.

42 Silva RAP, Chu Y, Miller JD, Mitchell IJ, Penninger JM, Faraci FM, et al. Impact of ace2 deficiency and oxidative stress on cerebrovascular function with aging. Stroke. 2012; 43(12):3358-63.

43 Lukiw WJ, Pogue A, Hill JM. Sars-cov-2 infectivity and neurological targets in the brain. Cell Mol Neurobiol. 2020:1-8.

44 Zheng J-L, Li G-Z, Chen S-Z, Wang J-J, Olson JE, Xia H-J, et al. Angiotensin converting enzyme $2 /$ ang-(1-7)/mas axis protects brain from ischemic injury with a tendency of agedependence. CNS Neurosci Ther. 2014;20(5): 452-9.

45 Noureddine FY, Altara R, Fan F, Yabluchanskiy A, Booz GW, Zouein FA. Impact of the renin-angiotensin system on the endothelium in vascular dementia: Unresolved issues and future perspectives. Int J Mol Sci. 2020; 21(12):4268.

46 Miners S, Kehoe PG, Love S. Cognitive impact of covid-19: looking beyond the short term. Alzheimers Res Ther. 2020;12(1):1-16.

47 Zegarra-Valdivia J, Vilca BNC, Tairo T, Munive V, Lastarria C. Neurological component in coronaviruses induced disease: systematic review of sars-cov, mers-cov, and sars-cov-2. OSF Preprints. 2020.

48 Desforges M, Le Coupanec A, Brison E, Meessen-Pinard M, Talbot PJ. Neuroinvasive and neurotropic human respiratory coronaviruses: potential neurovirulent agents in humans. Adv Exp Med Biol. 2014;807:75-96. 
49 Ritchie K, Chan D, Watermeyer T. The cognitive consequences of the covid-19 epidemic: collateral damage? Brain Commun. 2020; 2(2):fcaa069.

50 Ashour HM, Elkhatib WF, Rahman MM, Elshabrawy HA. Insights into the recent 2019 novel coronavirus (sars-cov-2) in light of past human coronavirus outbreaks. Pathogens. 2020;9(3): 186.

51 Ogier M, Andéol G, Sagui E, Dal Bo G. How to detect and track chronic neurologic sequelae of covid-19? use of auditory brainstem responses and neuroimaging for long-term patient follow-up. Brain Behav Immun Health. 2020. 5:100081.

52 Li Z, Liu T, Yang N, Han D, Mi X, Li Y, et al. Neurological manifestations of patients with covid-19: potential routes of sars-cov-2 neuroinvasion from the periphery to the brain. Front Med. 2020;14:533-41.

53 Meinhardt J, Radke J, Dittmayer C, Franz J, Thomas C, Mothes R, et al. Olfactory transmucosal sars-cov- 2 invasion as a port of central nervous system entry in individuals with covid-19. Nat Neurosci. 2021;24(2):168-75.

54 Thakur KT, Miller EH, Glendinning MD, AlDalahmah O, Banu MA, Boehme AK, et al Covid-19 neuropathology at columbia university irving medical center/new york presbyterian hospital. medRxiv. 2021.

55 Politi LS, Salsano E, Grimaldi M. Magnetic resonance imaging alteration of the brain in a patient with coronavirus disease 2019 (covid-19) and anosmia. JAMA Neurol. 2020; 77(8):1028-9.

56 Moein ST, Hashemian SM, Mansourafshar B Khorram-Tousi A, Tabarsi P, Doty RL. Smell dysfunction: a biomarker for covid-19. Int Forum Allergy Rhinol. 2020;10:944-50.

57 Insausti R, Marcos P, Arroyo-Jiménez MM, Blaizot X, Martínez-Marcos A. Comparative aspects of the olfactory portion of the entorhinal cortex and its projection to the hippocampus in rodents, nonhuman primates, and the human brain. Brain Res Bull. 2002;57(3-4) $557-60$.

58 De Leon MJ, DeSanti S, Zinkowski R, Mehta PD, Pratico D, Segal S, et al. MRI and CSF studies in the early diagnosis of Alzheimer's disease. J Intern Med. 2004;256(3):205-23.

59 Zubair AS, McAlpine LS, Gardin T, Farhadian S, Kuruvilla DE, Spudich S. Neuropathogen- esis and neurologic manifestations of the coronaviruses in the age of coronavirus disease 2019: a review. JAMA Neurol. 2020. 77(8):1018-27.

60 Black KL. Biochemical opening of the bloodbrain barrier. Adv Drug Deliv Rev. 1995 15(1-3):37-52.

61 Peng L, Liu J, Xu W, Luo Q, Chen D, Lei Z, et al. Sars-cov-2 can be detected in urine, blood, anal swabs, and oropharyngeal swabs specimens. J Med Virol. 2020;92(9):1676-80.

62 Lewis A, Frontera J, Placantonakis DG, Lighter J, Galetta S, Balcer L, et al. Cerebrospinal fluid in covid-19: a systematic review of the literature. J Neurol Sci. 2021;421:117316.
63 Hawkins BT, Davis TP. The blood-brain barrier/neurovascular unit in health and disease. Pharmacol Rev. 2005;57(2):173-85.

64 Jiang X, Andjelkovic AV, Zhu L, Yang T, Bennett MVL, Chen J, et al. Blood-brain barrier dysfunction and recovery after ischemic stroke. Prog Neurobiol. 2018;163-164:14471.

65 Stolp HB, Dziegielewska KM. Review: role of developmental inflammation and bloodbrain barrier dysfunction in neurodevelopmental and neurodegenerative diseases. Neuropathol Appl Neurobiol. 2009;35(2):132-46

66 Tahira AC, Verjovski-Almeida S, Ferreira ST. Dementia is an age-independent risk factor for severity and death in covid-19 inpatients. Alzheimers Dement. 2021

67 Sahraian MA, Azimi A, Navardi S, Ala S, Naser Moghadasi A. Evaluation of the rate of covid-19 infection, hospitalization and death among iranian patients with multiple sclerosis. Mult Scler Relat Disord. 2020;46:102472.

68 Lim K-H, Yang S, Kim S-H, Joo J-Y. Identifying new covid-19 receptor neuropilin-1 in severe alzheimer's diseases patients group brain using genome-wide association study approach. Res Sq. 2021.

69 Chachkhiani D, Soliman MY, Barua D, Isakadze M, Villemarette-Pittman NR, Devier DJ, et al. Neurological complications in a predominantly african american sample of covid-19 predict worse outcomes during hospitalization. Clin Neurol Neurosurg. 2020;197: 106173.

70 Sheraton M, Deo N, Kashyap R, Surani S. A review of neurological complications of $\mathrm{co}-$ vid-19. Cureus. 2020;12(5):e8192.

71 Liotta EM, Batra A, Clark JR, Shlobin NA Hoffman SC, Orban ZS, et al. Frequent neurologic manifestations and encephalopathyassociated morbidity in covid-19 patients. Ann Clin Transl Neurol. 2020;7(11):2221-30.

72 Mao L, Wang M, Chen S, He Q, Chang J, Hong C, et al. Neurological manifestations of hospitalized patients with covid-19 in $\mathrm{Wu}$ han, China: a retrospective case series study. MedRxiv. 2020

73 Romero-Sánchez CM, Díaz-Maroto I, Fernández-Díaz E, Sánchez-Larsen Á, LayosRomero A, García- García J, et al. Neurologic manifestations in hospitalized patients with covid-19: the albacovid registry. Neurology. 2020;95(8):e1060-70.

74 Nordvig AS, Fong KT, Willey JZ, Thakur KT, Boehme AK, Vargas WS, et al. Potential neurologic manifestations of covid-19. Neurol Clin Pract. 2021;11(2):e135-46.

75 Helms J, Kremer S, Merdji H, Clere-Jehl R, Schenck M, Kummerlen C, et al. Neurologic features in severe sars-cov-2 infection. N Engl J Med. 2020;382(23):2268-70.

76 Radmanesh A, Raz E, Zan E, Derman A, Kaminetzky $\mathrm{M}$. Brain imaging use and findings in covid-19: a single academic center experience in the epicenter of disease in the United States. AJNR Am J Neuroradiol. 2020;41(7): 1179-83.
77 Wang D, Hu B, Hu C, Zhu F, Liu X, Zhang J, et al. Clinical characteristics of 138 hospitalized patients with 2019 novel coronavirus-infected pneumonia in Wuhan, China. JAMA. 2020;323(11):1061-9.

78 Mercante G, Ferreli F, De Virgilio A, Gaino F, Di Bari M, Colombo G, et al. Prevalence of taste and smell dysfunction in coronavirus disease 2019. JAMA Otolaryngol Head Neck Surg. 2020; 146(8): 723-8. http://dx.doi. org/10.1001/jamaoto.2020.1155.08.

79 Ticinesi A, Cerundolo N, Parise A, Nouvenne A, Prati B, Guerra A, et al. Delirium in covid-19: epidemiology and clinical correlations in a large group of patients admitted to an academic hospital. Aging Clin Exp Res. 2020; 32(10):2159-66

80 Kennedy M, Helfand BKI, Gou RY, Gartaganis SL, Webb M, Moccia JM, et al. Delirium in older patients with covid-19 presenting to the emergency department. JAMA Netw Open. 2020;3(11):e2029540.

81 Garcez FB, Aliberti MJR, Poco PCE, Hiratsuka M, TakahashiSF, Coelho VA, et al. Delirium and adverse outcomes in hospitalized patients with covid-19. J Am Geriatr Soc. 2020;68(11):2440-6.

82 Bilaloglu S, Aphinyanaphongs Y, Jones S, Iturrate E, Hochman J, Berger JS. Thrombosis in hospitalized patients with COVID-19 in a New York City health system. JAMA. 2020; 324(8):799-801.

83 Merkler AE, Parikh NS, Mir S, Gupta A, Kamel H, Lin E, et al. Risk of ischemic stroke in patients with coronavirus disease 2019 (COVID-19) vs patients with influenza. JAMA Neurol. 2020;77(11):1366-72.

84 Zachariadis A, Tulbu A, Strambo D, Dumoulin A, Di Virgilio G. Transverse myelitis related to covid-19 infection. J Neurol. 2020; 267(12):3459-61.

85 Lechien JR, Chiesa-Estomba CM, De Siati DR, Horoi M, Le Bon SD, Rodriguez A, et al. Olfactory and gustatory dysfunctions as a clinical presentation of mild-to-moderate forms of the coronavirus disease (covid-19): a multicenter european study. Eur Arch Otorhinolaryngol. 2020;277(8):2251-61.

86 Toscano G, Palmerini F, Ravaglia S, Ruiz L, Invernizzi $\mathrm{P}$, Cuzzoni MG, et al. Guillain-Barré syndrome associated with SARS-CoV-2. N Engl J Med. 2020;382(26):2574-6.

87 Gutiérrez-Ortiz C, Méndez-Guerrero A, Rodrigo-Rey S, San Pedro-Murillo E, BermejoGuerrero L, Gordo-Mañas R, et al. Miller fisher syndrome and polyneuritis cranialis in covid-19. Neurology. 2020;95(5):e601-5.

88 Lantos JE, Strauss S, Lin E. Covid-19-associated miller fisher syndrome: Mri findings. Am J Neuroradiol. 2020;41(7):1184-6.

89 Sedaghat Z, Karimi N. Guillain barre syndrome associated with covid-19 infection: a case report. J Clin Neurosci. 2020;76:233-5.

90 Luo M, Guo L, Yu M, Wang H. The psychological and mental impact of coronavirus disease 2019 (covid-19) on medical staff and general public-a systematic review and metaanalysis. Psychiatry Res. 2020:113190. 
91 Whitley RJ. Viral encephalitis. N Engl J Med. 1990;323(4):242-50.

92 Johnson RT. Acute encephalitis. Clin Infect Dis. 1996;23(2):219-6.

93 Moir RD, Lathe R, Tanzi RE. The antimicrobial protection hypothesis of Alzheimer's disease. Alzheimers Dement. 2018;14(12): 1602-14.

94 Ye M, Ren Y, Lv T. Encephalitis as a clinical manifestation of covid-19. Brain Behav Immun. 2020;88:945.

95 Li Y, Fu L, Gonzales DM, Lavi E. Coronavirus neurovirulence correlates with the ability of the virus to induce proinflammatory cytokine signals from astrocytes and microglia. J Virol. 2004;78(7):3398-406.

96 Kanberg N, Ashton NJ, Andersson LM, Yilmaz A, Lindh M, Nilsson S, et al. Neurochemical evidence of astrocytic and neuronal injury commonly found in covid- 19 . Neurology. 2020;95(12):e1754-9.

97 Sun S-H, Chen Q, Gu H-J, Yang G, Wang Y-X, Huang X-Y, et al. A mouse model of sars-cov-2 infection and pathogenesis. Cell Host Microbe. 2020;28(1):124-33.

98 Yachou Y, El Idrissi A, Belapasov V, Ait Benali S. Neuroinvasion, neurotropic, and neuroinflammatory events of sars-cov-2: understanding the neurological manifestations in covid-19 patients. Neurol Sci. 2020 41:2657-69.

99 Steardo L, Steardo LJr, Zorec R, Verkhratsky A. Neuroinfection may contribute to pathophysiology and clinical manifestations of covid-19. Acta Physiol. 2020;229: e13473.

100 Murta V, Villarreal A, Ramos AJ. Sars-cov-2 impact on the central nervous system: Are astrocytes and microglia main players or merely bystanders? 2020. [Preprints].

101 Itzhaki RF, Cosby SL, Wozniak MA. Herpes simplex virus type 1 and alzheimer's disease: the autophagy connection. J Neurovirol. $2008 ; 14(1): 1-4$

102 Arbour N, Côté G, Lachance C, Tardieu M, Cashman NR, Talbot PJ. Acute and persistent infection of human neural cell lines by human coronavirus oc43. J Virol. 1999; 73(4):3338-50.

103 Arbour N, Ekandé S, Côté G, Lachance C, Chagnon F, Tardieu M, et al. Persistent infection of human oligodendrocytic and neuroglial cell lines by human coronavirus 229e. J Virol. 1999;73(4):3326-37.

104 Kempuraj D, Thangavel R, Natteru PA, Selvakumar GP, Saeed D, Zahoor H, et al. Neuroinflammation induces neurodegeneration. J Neurol Neurosurg Spine. 2016;1(1).

105 Serrano-Castro PJ, Estivill-Torrús G, Cabezudo-García P, Reyes-Bueno JA, Ciano Petersen N, Aguilar-Castillo MJ, et al. Impact of sars-cov-2 infection on neurodegenerative and neuropsychiatric diseases: a delayed pandemic? Neurologia. 2020;35(4): 245-51.

106 Chen WW, Zhang X, Huang WJ. Role of neuroinflammation in neurodegenerative diseases (Review). Mol Med Rep. 2016; 13(4):3391-6.

107 Paterson RW, Brown RL, Benjamin L, Nortley $\mathrm{R}$, Wiethoff $\mathrm{S}$, Bharucha $\mathrm{T}$, et al. The emerging spectrum of covid-19 neurology: clinical, radiological and laboratory findings. Brain. 2020;143(10):3104-20.

108 Reichard RR, Kashani KB, Boire NA, Constantopoulos E, Guo Y, Lucchinetti CF. Neuropathology of COVID-19: a spectrum of vascular and acute disseminated encephalomyelitis (ADEM)-like pathology. Acta Neuropathol. 2020;140(1):1-6.

109 Jaunmuktane Z, Mahadeva U, Green A, Sekhawat V, Barrett NA, Childs L, et al. Microvascular injury and hypoxic damage: emerging neuropathological signatures in covid-19. Acta neuropathologica. 2020; 140(3):397-400.

110 von Weyhern CH, Kaufmann I, Neff F, Kremer M. Early evidence of pronounced brain involvement in fatal covid-19 outcomes. Lancet. 2020;395(10241):e109.

111 Lee M-H, Perl DP, Nair G, Li W, Maric D, Murray $\mathrm{H}$, et al. Microvascular injury in the brains of patients with covid-19. N Engl J Med. 2021;384(5):481-3.

112 Solomon IH, Normandin E, Bhattacharyya S, Mukerji SS, Keller K, Ali AS, et al. Neuropathological features of covid-19. N Engl J Med. 2020;383(10):989-92.

113 Gulko E, Oleksk M, Gomes W, Ali S, Mehta $\mathrm{H}$, Overby $\mathrm{P}$, et al. MRI brain findings in 126 patients with covid-19: initial observations from a descriptive literature review. Am J Neuroradiol. 2020;41(12):2199-203.

114 Lin E, Lantos JE, Strauss SB, Phillips CD, Campion TR, Navi BB, et al. Brain imaging of patients with covid-19: findings at an academic institution during the height of the outbreak in new york city. AJNR Am J Neuroradiol. 2020;41(11):2001-8.

115 Kremer S, Lersy F, de Sèze J, Ferré JC, Maamar A, Carsin-Nicol B, et al. Brain mri findings in severe covid-19: a retrospective observational study. Radiology. 2020;297(2): E242-51.

116 Agarwal S, Jain R, Dogra S, Krieger P, Lewis A, Nguyen V, et al. Cerebral microbleeds and leukoencephalopathy in critically ill patients with covid-19. Stroke. 2020;51(9): 2649-55.

117 Benson JC, Hunt CH, Klaas JP, Kallmes DF. Intracranial microhemorrhages in the setting of covid-19: what we know so far. Neuroradiol J. 2021:19714009211004144.

118 Kirschenbaum D, Imbach LL, Rushing EJ, Frauenknecht KBM, Gascho D, Ineichen $\mathrm{BV}$, et al. Intracerebral endotheliitis and microbleeds are neuropathological features of covid-19. Neuropathol Appl Neurobiol. 2021;47(3):454-9.

119 Fitsiori A, Pugin D, Thieffry C, Lalive P, Vargas MI. Covid-19 is associated with an unusual pattern of brain microbleeds in critically ill patients. J Neuroimaging. 2020; 30(5):593-7.
120 Lersy F, Willaume T, Brisset JC, Collange O, Helms J, Schneider F, et al. Critical illnessassociated cerebral microbleeds for patients with severe covid-19: etiologic hypotheses. J Neurol. 2020:1-9.

121 Lu Y, Li X, Geng D, Mei N, Wu PY, Huang $\mathrm{CC}$, et al. Cerebral micro-structural changes in COVID-19 patients: an MRI-based 3-month Follow-up Study. EClinicalMedicine. 2020;25:100484.

122 Silva LS, Joao RB, Nogueira MH, Aventurato IK, de Campos BM, de Brito MR, et al. Functional and microstructural brain abnormalities, fatigue, and cognitive dysfunction after mild covid-19. medRxiv. 2021.

123 Xiong Q, Xu M, Li J, Liu Y, Zhang J, Xu Y, et al. Clinical sequelae of covid-19 survivors in wuhan, china: a Single-Centre Longitudinal study. Clin Microbiol Infect. 2021;27(1): 89-95.

124 Carfi A, Bernabei R, Landi F. Persistent symptoms in patients after acute covid-19. JAMA. 2020;324(6):603-5.

125 Townsend L, Dyer AH, Jones K, Dunne J, Mooney A, Gaffney F, et al. Persistent fatigue following sars-cov-2 infection is common and independent of severity of initial infection. PLoS One. 2020;15(11):e0240784.

126 Akter F, Mannan A, Mehedi HMH, Rob MA, Ahmed S, Salauddin A, et al. Clinical characteristics and short term outcomes after recovery from covid-19 in patients with and without diabetes in bangladesh. Diabetes Metab Syndr. 2020;14(6):2031-8.

127 Mazza MG, De Lorenzo R, Conte C, Poletti S, Vai B, Bollettini I, et al. Anxiety and depression in covid-19 survivors: role of inflammatory and clinical predictors. Brain Behav Immun. 2020;89:594-600.

128 Mazza MG, Palladini M, De Lorenzo R Magnaghi C, Poletti S, Furlan R, et al. Persistent psychopathology and neurocognitive impairment in covid-19 survivors: effect of inflammatory biomarkers at threemonth follow-up. Brain Behav Immun. 2021:94:138-47.

129 Zhou H, Lu S, Chen J, Wei N, Wang D, Lyu $\mathrm{H}$, et al. The landscape of cognitive function in recovered covid-19 patients. J Psychiatr Res. 2020;129:98-102.

130 Amalakanti S, Arepalli KVR, Jillella JP. Cognitive assessment in asymptomatic covid-19 subjects. Virusdisease. 2021;32(1):146-9.

131 Hampshire A, Trender W, Chamberlain S, Jolly A, Grant JE, Patrick F, et al. Cognitive deficits in people who have recovered from covid-19 relative to controls: an $\mathrm{n}=84,285$ online study. MedRxiv. 2020.

132 Helms J, Kremer S, Merdji H, Schenck M, Severac F, Clere-Jehl R, et al. Delirium and encephalopathy in severe covid-19: a cohort analysis of icu patients. Crit Care. 2020; 24(1):491-11

133 Fong TG, Davis D, Growdon ME, Albuquerque A, Inouye SK. The interface between delirium and dementia in elderly adults. Lancet Neurol. 2015;14(8):823-32. 
134 Garcez FB, Apolinario D, Campora F, Curiati JAE, Jacob-Filho W, Avelino-Silva TJ. Delirium and post-discharge dementia: results from a cohort of older adults without baseline cognitive impairment. Age Ageing. 2019;48(6):845-51.

135 Goldberg TE, Chen C, Wang Y, Jung E, Swanson A, Ing C, et al. Association of delirium with long-term cognitive decline: a meta-analysis. JAMA Neurol. 2020;77(11): 1373-81.

136 Pandharipande PP, Girard TD, Jackson JC, Morandi A, Thompson JL, Pun BT, et al. Long-term cognitive impairment after critical illness. N Engl J Med. 2013;369(14): 1306-16.

137 Fong TG, Jones RN, Shi P, Marcantonio ER, Yap L, Rudolph JL, et al. Delirium accelerates cognitive decline in alzheimer disease. Neurology. 2009;72(18):1570-5.

138 Cricco M, Simonsick EM, Foley DJ. The impact of insomnia on cognitive functioning in older adults. J Am Geriatr Soc. 2001; 49(9):1185-9.

139 Lin F, Chen DG, Vance DE, Ball KK, Mapstone M. Longitudinal relationships between subjective fatigue, cognitive function, and everyday functioning in old age. Int Psychogeriatr. 2013;25(2):275-85.

140 James BD, Wilson RS, Barnes LL, Bennett DA. Late-life social activity and cognitive decline in old age. J Int Neuropsychol Soc. 2011;17(6):998.

141 Schuitevoerder S, Rosen JW, Twamley EW, Ayers CR, Sones H, Lohr JB, et al. A metaanalysis of cognitive functioning in older adults with ptsd. J Anxiety Disord. 2013; 27(6):550-8.

142 Jorm AF. Is depression a risk factor for dementia or cognitive decline? Gerontology. 2000;46(4):219-27.

143 Taquet M, Luciano S, Geddes JR, Harrison PJ. Bidirectional associations between covid-19 and psychiatric disorder: retrospective cohort studies of 62,354 covid-19 cases in the USA. Lancet Psychiatry. 2021;8(2): $130-40$.

144 Hickie I, Davenport T, Wakefield D, Vollmer-Conna U, Cameron B, Vernon SD, et al. Post-infective and chronic fatigue syndromes precipitated by viral and non-viral pathogens: prospective cohort study. BMJ. 2006;333(7568):575.

145 Tenforde MW, Kim SS, Lindsell CJ, Billig Rose E, Shapiro NI, Files DC, et al. Symptom duration and risk factors for delayed return to usual health among outpatients with COVID-19 in a Multistate Health Care Systems Network: United States, MarchJune 2020. MMWR Morb Mortal Wkly Rep. 2020;69(30):993.

146 Havervall S, Rosell A, Phillipson M, Mangsbo SM, Nilsson P, Hober S, et al. Symptoms and functional impairment assessed 8 months after mild covid-19 among health care workers. JAMA. 2021; 325(19):2015-6.
147 Sudre CH, Murray B, Varsavsky T, Graham MS, Penfold RS, Bowyer RC, et al. Attributes and predictors of long covid. Nat Med. 2021; 27(4):626-31.

148 Graham EL, Clark JR, Orban ZS, Lim PH, Szymanski AL, Taylor C, et al. Persistent neurologic symptoms and cognitive dysfunction in non-hospitalized Covid-19 "long haulers". Ann Clin Transl Neurol. 2021;8(5):1073-85.

149 Rogers JP, Chesney E, Oliver D, Pollak TA, McGuire P, Fusar-Poli P, et al. Psychiatric and neuropsychiatric presentations associated with severe coronavirus infections: a system- atic review and meta-analysis with comparison to the covid-19 pandemic. Lancet Psychiatry. 2020;7(7):611-27.

150 Prescott HC, Girard TD. Recovery from severe covid-19: leveraging the lessons of survival from sepsis. JAMA. 2020;324(8):73940.

151 Lam MH, Wing YK, Yu MW, Leung CM, Ma RC, Kong AP, et al. Mental morbidities and chronic fatigue in severe acute respiratory syndrome survivors: long-term followup. Arch Intern Med. 2009;169(22):2142-7.

152 Huang C, Huang L, Wang Y, Li X, Ren L, Gu $\mathrm{X}$, et al. 6-month consequences of covid-19 in patients discharged from hospital: a cohort study. Lancet. 2021;397(10270):22032.

153 Zhao YM, Shang YM, Song WB, Li QQ, Xie $\mathrm{H}, \mathrm{Xu} \mathrm{QF}$, et al. Follow-up study of the pulmonary function and related physiological characteristics of covid-19 survivors three months after recovery. EClinicalMedicine. 2020;25:100463.

154 Stavem K, Ghanima W, Olsen MK, Gilboe HM, Einvik G. Prevalence and determinants of fatigue after covid-19 in non-hospitalized subjects: a population-based study. Int J Environ Res Public Health. 2021;18(4): 2030.

155 Wang H, Li R, Zhou Z, Jiang H, Yan Z, Tao $\mathrm{X}$, et al. Cardiac involvement in covid-19 patients: mid-term follow up by cardiovascular magnetic resonance. J Cardiovasc Magn Reson. 2021;23(1):1-12.

156 Puntmann VO, Carerj ML, Wieters I, Fahim M, Arendt C, Hoffmann J, et al. Outcomes of cardiovascular magnetic resonance imaging in patients recently recovered from coronavirus disease 2019 (covid-19). JAMA Cardiol. 2020;5(11):1265-73.

157 Shevlin M, McBride O, Murphy J, Miller JG, Hartman TK, Levita L, et al. Anxiety, depression, traumatic stress and covid-19-related anxiety in the uk general population during the covid-19 pandemic. BJPsych Open. 2020;6(6):e125.

158 Shah AS, Wong AW, Hague CJ, Murphy DT, Johnston JC, Ryerson CJ, et al. A prospective study of 12-week respiratory outcomes in covid-19-related hospitalisations. Thorax. 2021;76(4):402-4.

159 Pei G, Zhang Z, Peng J, Liu L, Zhang C, Yu $\mathrm{C}$, et al. Renal involvement and early prog- nosis in patients with COVID-19 pneumonia. J Am Soc Nephrol. 2020;31(6):115765.

160 An YW, Song S, Li WX, Chen YX, Hu XP Zhao J, et al. Liver function recovery of covid-19 patients after discharge, a follow-up study. Int J Med Sci. 2021;18(1):176.

161 Santos CY, Snyder PJ, Wu W-C, Zhang M, Echeverria A, Alber J. Pathophysiologic relationship between alzheimer's disease, cerebrovascular disease, and cardiovascular risk: a review and synthesis. Alzheimers Dement. 2017;7:69-87.

162 de Bruijn RF, Ikram MA. Cardiovascular risk factors and future risk of Alzheimer's disease. BMC Med. 2014;12(1):130.

163 Kuz'ma E, Lourida I, Moore SF, Levine DA, Ukoumunne OC, Llewellyn DJ. Stroke and dementia risk: a systematic review and meta-analysis. Alzheimers Dement. 2018; 14(11):1416-26.

164 Biessels GJ. Diagnosis and treatment of vascular damage in dementia. Biochim Biophys Acta. 2016;1862(5):869-77.

165 Sanyaolu A, Okorie C, Marinkovic A, Patidar R, Younis K, Desai P, et al. Comorbidity and its impact on patients with covid-19. SN Compr Clin Med. 2020:1-8.

166 Xie J, Tong Z, Guan X, Du B, Qiu H. Clinical characteristics of patients who died of coronavirus disease 2019 in china. JAMA Netw Open. 2020;3(4):e205619.

167 Clerkin KJ, Fried JA, Raikhelkar J, Sayer G, Griffin JM, Masoumi A, et al. Covid-19 and cardiovascular disease. Circulation. 2020; 141(20):1648-55.

168 Dweck MR, Bularga A, Hahn RT, Bing R, Lee KK, Chapman AR, et al. Global evaluation of echocardiography in patients with covid-19. Eur Heart J Cardiovasc Imaging. 2020;21(9):949-58

169 Brito D, Meester S, Yanamala N, Patel HB, Balcik BJ, Casaclang-Verzosa G, et al. High prevalence of pericardial involvement in college student athletes recovering from covid-19. JACC Cardiovasc Imaging. 2021; 14(3):541-55

170 Lindner D, Fitzek A, Bräuninger H, Aleshcheva G, Edler C, Meissner K, et al. Association of cardiac infection with sars-cov-2 in confirmed covid-19 autopsy cases. JAMA Cardiol. 2020;5(11):1281-5.

171 Mitrani RD, Dabas N, Goldberger JJ. Covid-19 cardiac injury: implications for longterm surveillance and outcomes in survivors. Heart Rhythm. 2020;17(11):1984-90.

172 Jain SS, Liu Q, Raikhelkar J, Fried J, Elias P, Poterucha TJ, et al. Indications for and findings on transthoracic echocardiography in covid-19. J Am Soc Echocardiogr. 2020; 33(10):1278-84.

173 Lodigiani C, Iapichino G, Carenzo L, Cecconi M, Ferrazzi P, Sebastian T, et al. Venous and arterial thromboembolic complications in covid-19 patients admitted to an academic hospital in milan, italy. Thrombosis research. 2020;191:9-14. 
174 Klok FA, Kruip MJHA, Van der Meer NJM, Arbous MS, Gommers DAMPJ, Kant KM, et al. Incidence of thrombotic complications in critically ill icu patients with covid- 19 . Thromb Res. 2020;191:145-7.

175 Al-Samkari H, Karp Leaf RS, Dzik WH, Carlson JCT, Fogerty AE, Waheed A, et al. Covid-19 and coagulation: bleeding and thrombotic manifestations of sars-cov- 2 infection. Blood. 2020;136(4):489-500.

176 Chan NC, Weitz JI. Covid-19 coagulopathy, thrombosis, and bleeding. Blood. 2020; 136(4):381-3.

177 Wichmann D, Sperhake JP, Lütgehetmann M, Steurer S, Edler C, Heinemann A, et al. Autopsy findings and venous thromboembolism in patients with covid-19: a prospective cohort study. Ann Intern Med. 2020; 173(4):268-77.

178 Lax SF, Skok K, Zechner P, Kessler HH, Kaufmann N, Koelblinger C, et al. Pulmonary arterial thrombosis in covid-19 with fatal outcome: results from a prospective, single- center, clinicopathologic case series. Ann Intern Med. 2020;173(5):350-61.

179 Tang N, Li D, Wang X, Sun Z. Abnormal coagulation parameters are associated with poor prognosis in patients with novel coronavirus pneumonia. J Thromb Haemost. 2020;18(4):844-7.

180 Zhou F, Yu T, Du R, Fan G, Liu Y, Liu Z, et al. Clinical course and risk factors for mortality of adult inpatients with covid-19 in Wuhan, China: a retrospective cohort study. Lancet. 2020;395(10229):1054-62.

181 Guan W, Ni Z, Hu Y, Liang W, Ou C, He J, et al. Clinical characteristics of coronavirus disease 2019 in China. N Engl J Med. 2020; 382(18):1708-20.

182 McFadyen JD, Stevens H, Peter K. The emerging threat of (micro) thrombosis in covid-19 and its therapeutic implications. Circ Res. 2020;127(4):571-87.

183 Altisent OA-J, Puri R, Rodés-Cabau J. Embolic protection devices during tavi: current evidence and uncertainties. Rev Esp Cardiol. 2016;69(10):962-72.

184 Varga Z, Flammer AJ, Steiger P, Haberecker M, Andermatt R, Zinkernagel AS, et al. Endothelial cell infection and endotheliitis in covid-19. Lancet. 2020;395(10234): $1417-8$.

185 Ollivier M, Bertrand A, Clarençon F, Gerber $S$, Deltour S, Domont F, et al. Neuroimaging features in posterior reversible encephalopathy syndrome: a pictorial review. J Neurol Sci. 2017;373:188-200.

186 Deibler AR, Pollock JM, Kraft RA, Tan H, Burdette JH, Maldjian JA. Arterial spin-labeling in routine clinical practice, part 3: hyperperfusion patterns. AJNR Am J Neuroradiol. 2008;29(8):1428-35.

187 Feugeas M-CH, Gaudemer A, Lescure X, Dossier A, Sonneville R, Ehmer C, et al. Covid-19 and dysregulated cerebral perfusion: observations with multi- modal mri. medRxiv. 2020.
188 Franceschi AM, Ahmed O, Giliberto L, Castillo M. Hemorrhagic posterior reversible encephalopathy syndrome as a manifestation of COVID-19 infection. AJNR Am J Neuroradiol. 2020;41(7):1173-6.

189 Hernández-Fernández F, Sandoval Valencia $\mathrm{H}$, Barbella-Aponte RA, Collado-Jiménez R, Ayo-Martín Ó, Barrena C, et al. Cerebrovascular disease in patients with covid-19: neuroimaging, histological and clinical description. Brain. 2020;143(10): 3089-103.

190 Uginet M, Breville G, Hofmeister J, Machi $\mathrm{P}$, Lalive PH, Rosi A, et al. Cerebrovascular complications and vessel wall imaging in covid-19 encephalopathy: a Pilot Study. Clin Neuroradiol. 2021:1-7.

191 Becker RC. Anticipating the long-term cardiovascular effects of covid-19. J Thromb Thrombolysis. 2020;50:512-24.

192 Libby P, Loscalzo J, Ridker PM, Farkouh ME, Hsue PY, Fuster V, et al. Inflammation, immunity, and infection in atherothrombosis: Jacc review topic of the week. J Am Coll Cardiol. 2018;72(17):2071-81.

193 Ratchford SM, Stickford JL, Province VM, Stute N, Augenreich MA, Koontz LK, et al. Vascular alterations among young adults with sars-cov-2. Am J Physiol Heart Circ Physiol. 2021;320(1):H404-10.

194 Deckers K, Camerino I, van Boxtel MP, Verhey FR, Irving K, Brayne C, et al. Dementia risk in renal dysfunction: a systematic review and meta-analysis of prospective studies. Neurology. 2017;88(2):198-208.

195 Solfrizzi V, Scafato E, Custodero C, Loparco F, Ciavarella A, Panza F, et al. Liver fibrosis score, physical frailty, and the risk of dementia in older adults: the Italian Longitudinal Study on aging. Alzheimers Dement. 2020;6(1):e12065

196 Kim HM, Lee YH, Han K, Lee BW, Kang ES, Kim J, et al. Impact of diabetes mellitus and chronic liver disease on the incidence of dementia and all-cause mortality among patients with dementia. Medicine. 2017; 96(47):e8753.

197 Gupta A, Madhavan MV, Sehgal K, Nair N, Mahajan S, Sehrawat TS, et al. Extrapulmonary manifestations of covid-19. Nat Med. 2020;26(7):1017-32.

198 Lizardo-Thiebaud MJ, Cervantes-Alvarez E, Limon-de la Rosa N, Tejeda-Dominguez F, Palacios-Jimenez M, Méndez-Guerrero O, et al. Direct or collateral liver damage in SARS-CoV-2-infected patients. Semin Liver Dis. 2020;40(3):321-30.

199 Penninger J, Imai Y, Kuba K. The discovery of angiotensin-converting enzyme 2 and its role in acute lung injury in mice. Exp Physiol. 2008;93(5):543-8.

200 Li Y, Zhou W, Yang L, You R. Physiological and pathological regulation of ace2, the sars-cov-2 receptor. Pharmacol Res. 2020; 157:104833.

201 Güneyli S, Atçeken Z, Doğan H, Altınmakas E, Atasoy KÇ. Radiological approach to co- vid-19 pneumonia with an emphasis on chest CT. Diagn Interv Radiol. 2020;26(4): 323.

202 Li Y, Shi J, Xia J, Duan J, Chen L, Yu X, et al. Asymptomatic and symptomatic patients with non-severe coronavirus disease (covid-19) have similar clinical features and virological courses: a retrospective single center study. Front Microbiol. 2020;11:1570.

203 Lan L, Xu D, Xia C, Wang S, Yu M, Xu H. Early CT findings of coronavirus disease 2019 (covid-19) in asymptomatic children: a single-center experience. Korean J Radiol. 2020;21:919.

204 Tzotzos SJ, Fischer B, Fischer H, Zeitlinger $\mathrm{M}$. Incidence of ards and outcomes in hospitalized patients with covid-19: a global literature survey. Crit Care. 2020;24(1):516-4.

205 Leonard-Lorant I, Delabranche X, Severac F, Helms J, Pauzet C, Collange O, et al. Acute pulmonary embolism in covid-19 patients on CT angiography and relationship to d-dimer levels. Radiology. 2020:201561.

206 Borczuk AC, Salvatore SP, Seshan SV, Patel SS, Bussel JB, Mostyka M, et al. Covid-19 pulmonary pathology: a multi-institutional autopsy cohort from italy and New York City. Mod Pathol. 2020;33(11):2156-68.

207 Bussani R, Schneider E, Zentilin L, Collesi C, Ali H, Braga L, et al. Persistence of viral rna, pneumocyte syncytia and thrombosis are hallmarks of advanced covid-19 pathology. EBioMedicine. 2020;61:103104.

208 Fan H, Tang X, Song Y, Liu P, Chen Y. Influence of covid-19 on cerebrovascular disease and its possible mechanism. Neuropsychiatr Dis Treat. 2020;16:1359-67.

209 Eltzschig HK, Carmeliet P. Hypoxia and inflammation. N Engl J Med. 2011;364(7): 656-65.

210 Mahammedi A, Ramos A, Bargalló N, Gaskill M, Kapur S, Saba L, et al. Brain and lung imaging correlation in patients with covid-19: could the severity of lung disease reflect the prevalence of acute abnormalities on neuroimaging? a global multicenter observational study. AJNR Am J Neuroradiol. 2021;42(6):1008-16

211 Vasarmidi E, Tsitoura E, Spandidos DA, Tzanakis N, Antoniou KM. Pulmonary fibrosis in the aftermath of the COVID-19 era (review). Exp Ther Med. 2020;20(3):255760.

212 Salehi S, Reddy S, Gholamrezanezhad A. Long-term pulmonary consequences of coronavirus disease 2019 (covid-19): what we know and what to expect. J Thorac Imaging. 2020;35(4):W87-9.

213 Baker HA, Safavynia SA, Evered LA. The "third wave": impending cognitive and functional decline in covid-19 survivors. $\mathrm{Br}$ J Anaesth. 2021;126(1):44-7.

214 Sasannejad C, Ely EW, Lahiri S. Long-term cognitive impairment after acute respiratory distress syndrome: a review of clinical impact and pathophysiological mechanisms. Crit Care. 2019;23(1):352. 
215 Zhou Y, Ren Q, Chen G, Jin Q, Cui Q, Luo $\mathrm{H}$, et al. Chronic kidney diseases and acute kidney injury in patients with covid-19: Evidence from a meta-analysis. Front Med. 2020;7:588301.

216 Hirsch JS, Ng JH, Ross DW, Sharma P, Shah $\mathrm{HH}$, Barnett RL, et al. Acute kidney injury in patients hospitalized with covid-19. Kidney Int. 2020;98(1):209-18.

217 Gupta S, Coca SG, Chan L, Melamed ML, Brenner SK, Hayek SS, et al. Aki treated with renal replacement therapy in critically ill patients with covid-19. J Am Soc Nephrol. 2021;32(1):161-76.

218 Santoriello D, Khairallah P, Bomback AS, Xu K, Kudose S, Batal I, et al. Postmortem kidney pathology findings in patients with covid-19. J Am Soc Nephrol. 2020;31(9): 2158-67.

219 Bassegoda O, Huelin P, Ariza X, Solé C, Juanola A, Gratacós-Ginès J, et al. Development of chronic kidney disease after acute kidney injury in patients with cirrhosis is common and impairs clinical outcomes. J Hepatol. 2020;72(6):1132-9.

220 Malek M. Brain consequences of acute kidney injury: focusing on the hippocampus. Kidney Res Clin Pract. 2018;37(4):315.

221 Fan Z, Chen L, Li J, Cheng X, Yang J, Tian C, et al. Clinical features of covid-19-related liver functional abnormality. Clin Gastroenterol Hepatol. 2020;18(7):1561-6.

222 Nardo AD, Schneeweiss-Gleixner M, Bakail M, Dixon ED, Lax SF, Trauner M. Pathophysiological mechanisms of liver injury in COVID-19. Liver Int. 2021;41(1):20-32.

223 Zhang C, Shi L, Wang FS. Liver injury in covid-19: management and challenges. Lancet Gastroenterol Hepatol. 2020;5(5):428-30.

224 Chen T, Wu D, Chen H, Yan W, Yang D, Chen G, et al. Clinical characteristics of 113 deceased patients with coronavirus disease 2019: retrospective study. BMJ. 2020;368: m1091.

225 Lei F, Liu YM, Zhou F, Qin JJ, Zhang P, Zhu $\mathrm{L}$, et al. Longitudinal association between markers of liver injury and mortality in covid-19 in china. Hepatology. 2020;72(2): 389-98.

226 Wang S, Xu J, Luo P, Yang L, Song S, Tan X, et al. Plasma metabolomic profiles and clinical features in recovered covid-19 patients without previous underlying diseases 3 months after discharge. Res Sq. 2020.

227 Argenziano MG, Bruce SL, Slater CL, Tiao JR, Baldwin MR, Barr RG, et al. Characterization and clinical course of 1,000 patients with coronavirus disease 2019 in New York: retrospective case series. BMJ. 2020;369.

228 Madjid M, Safavi-Naeini P, Solomon SD, Vardeny O. Potential effects of coronaviruses on the cardiovascular system: a review. JAMA Cardiol. 2020;5(7):831-40.

229 Onder G, Rezza G, Brusaferro S. Case-fatality rate and characteristics of patients dying in relation to covid-19 in Italy. JAMA. 2020; 323(18):1775-6.
230 Fried LP, Ferrucci L, Darer J, Williamson JD, Anderson G. Untangling the concepts of disability, frailty, and comorbidity: implications for improved targeting and care. J Gerontol A Biol Sci Med Sci. 2004;59(3): 255-63.

231 Abdel-Mannan O, Eyre M, Löbel U, Bamford A, Eltze C, Hameed B, et al. Neurologic and radiographic findings associated with covid-19 infection in children. JAMA Neurol. 2020;77(11):1440-5.

232 Ludvigsson JF. Systematic review of covid-19 in children shows milder cases and a better prognosis than adults. Acta Paediatr. 2020;109(6):1088-95.

233 Ott A, Breteler MM, Harskamp Fv., Stijnen T, Hofman A. Incidence and risk of dementia: the rotterdam study. Am J Epidemiol. 1998;147(6):574-80.

234 Chen J, Jiang Q, Xia X, Liu K, Yu Z, Tao W, et al. Individual variation of the sars-cov-2 receptor ace 2 gene expression and regulation. Aging Cell. 2020;19(7):e13168.

235 Ciaglia E, Vecchione C, Puca AA. Covid-19 infection and circulating ace 2 levels: Protective role in women and children. Front Pediatr. 2020;8:206.

236 Yoon HE, Kim EN, Kim MY, Lim JH, Jang IA, Ban TH, et al. Age-associated changes in the vascular renin-angiotensin system in mice. Oxid Med Cell Longev. 2016;2016: 6731093.

237 Mueller AL, McNamara MS, Sinclair DA. Why does covid-19 disproportionately affect older people? Aging. 2020;12(10):9959.

238 Aw D, Silva AB, Palmer DB. Immunosenescence: emerging challenges for an ageing population. Immunology. 2007; 120(4): 435-46.

239 Polidori MC, Maggi S, Mattace-Raso F, Pilotto A. The unavoidable costs of frailty: a geriatric perspective in the time of covid-19. Geriatric Care. 2020;6(1).

240 Franceschi C, Garagnani P, Vitale G, Capri M, Salvioli S. Inflammaging and "Garb-aging”. Trends Endocrinol Metab. 2017;28(3): 199-212.

241 Weisberg SP, Connors TJ, Zhu Y, Baldwin MR, Lin WH, Wontakal S, et al. Distinct antibody responses to sars-cov-2 in children and adults across the covid-19 clinical spectrum. Nat Immunol. 2021;22(1):25-31.

242 Akbar AN, Gilroy DW. Aging immunity may exacerbate covid-19. Science. 2020; 369(6501):256-7.

243 Ma Y, Hou L, Yang X, Huang Z, Yang X, Zhao N, et al. The association between frailty and severe disease among covid-19 patients aged over 60 years in china: a prospective cohort study. BMC Med. 2020;18(1): 274-8.

244 Maltese G, Corsonello A, Di Rosa M, Soraci L, Vitale C, Corica F, et al. Frailty and covid-19: a systematic scoping review. J Clin Med. 2020;9(7):2106

245 Pilotto A, Custodero C, Maggi S, Polidori MC, Veronese N, Ferrucci L. A multidimen- sional approach to frailty in older people. Ageing Res Rev. 2020;60:101047.

246 Skloot GS. The effects of aging on lung structure and function. Clin Geriatr Med. 2017;33(4):447-57.

247 Kundi H, Cetin EHÖ, Canpolat U, Aras S, Celik O, Ata N, et al. The role of frailty on adverse outcomes among older patients with covid-19. J Infect. 2020;81(6):944-51.

248 Hewitt J, Carter B, Vilches-Moraga A, Quinn TJ, Braude P, Verduri A, et al. The effect of frailty on survival in patients with covid-19 (cope): a multicentre, european, observational cohort study. Lancet Public Health. 2020;5(8):e444-51

249 Ha"gg S, Jylha"va” J, Wang Y, Xu H, Metzner C, Annetorp M, et al. Age, frailty, and comorbidity as prognostic factors for short-term outcomes in patients with coronavirus disease 2019 in geriatric care. J Am Med Dir Assoc. 2020;21(11):1555-9.

250 Jin JM, Bai P, He W, Wu F, Liu XF, Han DM, et al. Gender differences in patients with covid-19: focus on severity and mortality. Front Public Health. 2020;8:152

251 Peckham H, de Gruijter NM, Raine C, Radziszewska A, Ciurtin C, Wedderburn LR, et al. Male sex identified by global covid-19 meta-analysis as a risk factor for death and ITU admission. Nat Commun. 2020; 11(1):6317.

252 Abedi V, Olulana O, Avula V, Chaudhary D, Khan A, Shahjouei S, et al. Racial, economic, and health inequality and covid-19 infection in the united states. J Racial Ethn Health Disparities. 2021;8(3):732-42.

253 Holmes L, Enwere M, Williams J, Ogundele B, Chavan P, Piccoli T, et al. Black-white risk differentials in covid-19 (sars-cov2) transmission, mortality and case fatality in the united states: translational epidemiologic perspective and challenges. Int J Environ Res Public Health. 2020;17(12):4322.

254 Macias Gil R, Marcelin JR, Zuniga-Blanco B, Marquez C, Mathew T, Piggott DA. Covid-19 pandemic: disparate health impact on the hispanic/latinx population in the united states. J Infect Dis. 2020;222(10):1592-5.

255 Hatcher SM, Agnew-Brune C, Anderson M, Zambrano LD, Rose CE, Jim MA, et al. Covid-19 among american Indian and Alaska native persons - 23 states, January 31-July 3, 2020. MMWR Morb Mortal Wkly Rep. 2020;69(34):1166.

256 Tai DBG, Shah A, Doubeni CA, Sia IG Wieland ML. The disproportionate impact of covid-19 on racial and ethnic minorities in the united states. Clin Infect Dis. 2021; 72(4):703-6.

257 Ghosh S, Klein RS. Sex drives dimorphic immune responses to viral infections. J Immunol. 2017;198(5):1782-90.

258 Viveiros A, Rasmuson J, Vu J, Mulvagh SL, Yip CYY, Norris CM, et al. Sex differences in covid-19: candidate pathways, genetics of ace2, and sex hormones. Am J Physiol Heart Circ Physiol. 2021;320(1):H296-304. 
259 Klein SL, Dhakal S, Ursin RL, Deshpande S, Sandberg K, Mauvais-Jarvis F. Biological sex impacts covid-19 outcomes. PLoS Pathog. 2020;16(6):e1008570.

260 Hou Y, Zhao J, Martin W, Kallianpur A, Chung MK, Jehi L, et al. New insights into genetic susceptibility of covid-19: an ace2 and tmprss2 polymorphism analysis. BMC Med. 2020;18(1):216-8.

261 Bunyavanich S, Grant C, Vicencio A. Racial/ethnic variation in nasal gene expression of transmem- brane serine protease 2 (tmprss2). JAMA. 2020;324(15):1567-8.

262 Havranek EP, Mujahid MS, Barr DA, Blair IV, Cohen MS, Cruz-Flores S, et al. Social determinants of risk and outcomes for cardiovascular disease: a scientific statement from the american heart association. Circulation. 2015;132(9):873-98.

263 Zuberi T, Patterson EJ, Stewart QT. Race, methodology, and social construction in the genomic era. Ann Am Acad Pol Soc Sci. 2015;661(1):109-27.

264 Kurian AK, Cardarelli KM. Racial and ethnic differences in cardiovascular disease risk factors: a systematic review. Ethn Dis. 2007; 17(1): 143 .

265 Glymour MM, Manly JJ. Lifecourse social conditions and racial and ethnic patterns of cognitive aging. Neuropsychol Rev. 2008; 18(3):223-54.

266 Myers EM. Compounding health risks and increased vulnerability to sars-cov-2 for racial and ethnic minorities and low socioeconomic status individuals in the United States. 2020. [Preprints].

267 Biehl M, Sese D. Post-intensive care syndrome and covid-19-implications post pandemic. Cleve Clin J Med. 2020.

268 Hope AA, Johnson A, McPeake J, Felt $\mathrm{H}$, Sevin CM, Mikkelsen ME, et al. Establishing a peer support program for survivors of $\mathrm{CO}^{-}$ vid-19: a report from the critical and acute illness recovery organization. Am J Crit Care. 2021;30(2):150-4.

269 Dennis A, Wamil M, Kapur S, Alberts J, Badley A, Decker GA, et al. Multi-organ impairment in low-risk individuals with long covid. medRxiv. 2020.

270 Haynes N, Cooper LA, Albert MA. At the heart of the matter: unmasking and addressing covid-19's toll on diverse populations. Circulation. 2020;142(2):105-7.

$271 \mathrm{Wu} \mathrm{Z}$, McGoogan JM. Characteristics of and important lessons from the coronavirus disease 2019 (covid-19) outbreak in China: summary of a report of 72,314 cases from the chinese center for disease control and prevention. JAMA. 2020;323(13):1239-42.

272 Pereira A. Long-term neurological threats of covid-19: a call to update the thinking about the outcomes of the coronavirus pandemic. Front Neurol. 2020;11:308 